B-1

\title{
NUMERICAL ANALYSIS OF THE IOSIPESCU SPECIMEN FOR $\neg, \uparrow$ COMPOSITE MATERIALS
}

\author{
H. Ho, M.Y. Tsai, J. Morton \\ Department of Engineering Science and Mechanics \\ Virginia Polytechnic Institute and State University \\ Blacksburg VA 24061-0219 \\ and \\ G. L. Farley \\ US Army Aerostructures Directorate \\ NASA Langley Research Center \\ Hampton VA 23665-5225
}

\begin{abstract}
A finite element analysis of the Iosipescu shear test for unidirectional and cross-ply composites is presented. It is shown that an iterative analysis procedure must be used to model the fixture-specimen kinematics. The correction factors which are needed to compensate for the nonuniformity of stress distribution in calculating shear modulus are shown to be dependent on the material orthotropic ratio and the finite element loading models. Test section strain distributions representative of typical graphite-epoxy specimen are also presented.
\end{abstract}

Keywords: Numerical Analysis, Composite Materials, Iosipescu Specimen, Shear Modulus, Correction Factors

\section{INTRODUCTION}

The development and evaluation of in-plane shear test methods for the determination of shear modulus and strength has received considerable experimental and analytical attention from the composite materials industry, [1-5]. An ideal shear test method would produce a pure and uniform shear stress field in the test section of the specimen throughout the linear and nonlinear response regimes. Although the Iosipescu shear test method does not possess these ideal characteristics, it has gained wide acceptance for measuring the in-plane shear response of composite materials.

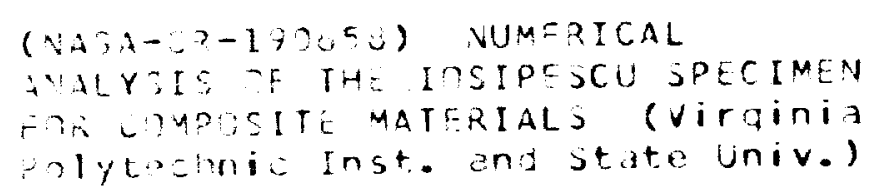


Two versions of the Iosipescu shear fixture and specimen configuration $[4,6]$ have been developed for composite materials, as depicted in Figs. 1 and 2. The original fixture (W1) produced a very small region of uniform shear stress and significant normal strains in the specimen test section. To overcome these deficiencies a modified fixture (W2) and specimen configuration [6] were developed. The modified fixture and specimen produced a larger test section, larger fixture-to-specimen contact regions and the innermost fixture-to-specimen contact points were moved farther away from the test section. The uniform shear stress region increased but normal strains still exist in the test section [7].

A considerable amount of experimentation and numerical analysis of the Iosipescu shear test have been performed [6-19]. Numerical studies have proven useful in understanding the influence on shear response of notch angle and radius [6], ply orientation $[6,7,11,13,16]$ as well as failure mechanisms and failure location [13], uniformity of stress-strain distribution in the test section $[7-9,11-16]$ and the development of shear modulus correction factors $[7,11,16]$. In any numerical study it is essential to represent accurately the kinematics of the fixture and specimen because boundary conditions and load introduction methods can significantly influence the stress state in the test section and the predicted failure location.

Unfortunately, there seems to be a lack of consensus of how to represent the boundary conditions and load introduction in the Iosipescu specimen. For example, Barnes et al. [13] used uniformly distributed applied forces, Sullivan et al. [9] used concentrated forces and Walrath and Adams [8] used prescribed vertical (y) displacements at the specimen-fixture contact regions in their finite element analyses of the W1 test specimen. The use of concentrated forces can cause significant local deformations in the specimen and are unrepresentative of the experimentally observed deformations. A uniform applied force assumes the applied force distribution is known $a$ priori. In recent finite element analyses of the W2 specimen by Adams and Walrath [6] and Pindera et al. [11,16], prescribed vertical displacement loading conditions were used but different types of constraints (hinges, $u=v=0$, and rollers, $v=0$ ) were applied to the stationary part of the specimen-fixture contact regions. Furthermore, the same loading condition was applied to the $0^{\circ}$ and $90^{\circ}$ specimens $[11,16]$.

The objective of this study is to conduct a linear-elastic finite element analysis of the modified Iosipescu shear specimen using a more realistic method of modeling the 
load transfer between the fixture and specimen and the displacement conditions at the specimen/fixture interface. The analysis is based upon an iterative scheme without any bias on the load distribution into the specimen. The reaction force distribution along the fixture-to-specimen contact region, the strain state in the specimen and the shear modulus correction factors are evaluated. Three fiber orientations $\left(0^{\circ}, 90^{\circ}\right.$ and $\left.0^{\circ} / 90^{\circ}\right)$ are used in the analysis along with three materials having different orthotropic ratios (typical values of graphite-, Kevlar- and glass-epoxy).

\section{FINITE ELEMENT MODELS}

In the modified Iosipescu shear test, the left end section of the specimen is clamped into the stationary part of the fixture and the right end section of the specimen is clamped into the movable part of the fixture, see Fig. 2a. Assuming that the clamping process does not introduce any significant strains in the specimen, load is transferred only from the fixture to the specimen along the upper fixture-to-specimen contact region of the movable portion of the fixture. The lower fixture-to-specimen contact region of the movable portion of the fixture cannot "pull" on the specimen because it is not mechanically attached to the specimen. That is, tensile forces cannot be applied along the lower edge of the specimen by the fixture. However, a reaction force is developed between the specimen and fixture along the lower edge of the movable part of the fixture because the lower contact region of the fixture prohibits rotation of the specimen keeping the upper and lower surfaces parallel and horizontal, as depicted in Fig. 3.

Local in-plane bending of the specimen occurs as load is applied to the specimen, as depicted in Fig. 3b. Along the outboard region of the upper fixture-to-specimen contact region and along the inboard region of the lower fixture-to-specimen contact region (movable portion of the fixture), the specimen can progressively separate from the fixture as a function of the applied load, see Fig. 3b, reducing the length of the contact region. A similar set of deformations occurs on the fixed portion of the specimen.

In this study, the distance from the notch axis to the inner most load point was $7.0 \mathrm{~mm}$. The mechanical properties of the three materials are presented in Table 1 . The finite element model had 1468 membrane finite elements, see Fig. 4. Close to the notch root, the elements are refined such that the reduction of strains to near zero at the free boundary are achieved. Prescribed displacements, $v=\delta=-0.05 \mathrm{~mm}$, were applied to the 
fixture-to-specimen contact regions on the movable part of the fixture. The ABAQUS and PATRAN codes were used for calculations and pre-, post processing, respectively.

The sequence of steps for application of boundary conditions and applied displacements in this study are as follows:

1. Displacement constraints $(v=0$ or $u=v=0$ ) to eliminate rigid body motion of the specimen are applied along the fixture-to-specimen contact region on the stationary (left) part of the specimen, see Fig. 5.

2. Uniformly applied displacements are applied along the fixture-to-specimen contact region on the movable (right) part of the specimen, see Fig. 5.

3. Reaction forces are calculated at the nodes where the applied and constrained displacements are introduced. Displacements along the fixture-to-specimen contact region are also calculated.

4. If any reaction force were tensile or if the specimen interfered with the fixture (displacement interference) then the displacement constraint or the applied displacement is changed or removed from that finite element node.

5. The analysis is performed with an updated set of applied displacements and boundary condition and the process is repeated starting with step 3 until convergence occurs.

6. When convergence occurs the load applied to the specimen is the sum of the reaction forces on the movable (right) portion of the specimen.

\section{RESULTS AND DISCUSSION}

\section{Force Distribution Along The Specimen-to-fixture Contact Region}

Solution convergence usually occurred within 3 or 4 iterations. The resulting displacement and reaction force distribution was different for each of the $0^{\circ}, 90^{\circ}$ and $0^{\circ} / 90^{\circ}$ specimens, as depicted in Fig. 6. These force distributions are a function of the ply orientation and are representative of neither the concentrated nor uniformly distributed force conditions applied by others [9-13]. The load distribution along the upper fixture-to-specimen contact region on the movable part of the fixture is highly nonlinear with the highest forces closest to the center of the specimen. The force distribution along the upper surface of the movable part is not the same as the force distribution along the lower surface. The force distribution at the innermost fixture-tospecimen contact region on the $90^{\circ}$ specimen is narrower than for the other ply 
orientations because in-plane bending occurs causing the specimen to pull away from the fixture. The force distribution of the $0^{\circ} / 90^{\circ}$ specimen is approximately the average of the $0^{\circ}$ and $90^{\circ}$ specimens.

\section{Strain State In The Specimen}

\section{Test section}

The normal and shear strains, normalized with respect to the average shear strains across the test section, are shown in Figs. $7-9$ for $0^{\circ}, 90^{\circ}$ and $0^{\circ} / 90^{\circ}$ specimens, respectively. The horizontal normal strains, $\varepsilon_{x}$, are negligible for all $0^{\circ}, 90^{\circ}$ and $0^{\circ} / 90^{\circ}$ specimens because no horizontal constraints are applied which is consistent with experimentally observed full-field results [7]. The compressive transverse normal strains, $\varepsilon_{y}$, are negligible for $90^{\circ}$ and $0^{\circ} / 90^{\circ}$ specimens but are significant for the $0^{\circ}$ specimens. As shown in Fig. 7 for the $0^{\circ}$ specimens, $\varepsilon_{y}$ reaches a maximum at the center of the specimen and decreases to zero at the notch root. The $\varepsilon_{y}$ strain distribution between notch tips (at $\mathrm{x}=0$ ) for the $0^{\circ}$ specimen is approximately a parabolic shape. At the center of the specimen, $\varepsilon_{y}$ is 24.4 percent of $\gamma_{\text {avg }}$ for graphite-epoxy and is 9.5 percent and 12.3 percent of $\gamma_{\text {avg }}$ for the Kevlar-epoxy and glass-epoxy, respectively. The compressive forces at the inner most fixture-to-specimen contact region creates $\varepsilon_{y}$ strains in the test section of the $0^{\circ}$ specimens, see Fig. 7. The $\varepsilon_{y}$ strains are created in the test section because the $0^{\circ}$ specimens bend and compress due to the low transverse stiffness of the laminate. The transverse compression of the $0^{\circ}$ specimens decreases with increasing distance from the inner most specimen-to-fixture contact region. The $90^{\circ}$ and $0^{\circ} / 90^{\circ}$ specimens experience negligible $\varepsilon_{y}$ strains, see Figs. 8 and 9 , in the test section because the $90^{\circ}$ fibers resists the transverse compression of the specimen.

The shear strain contours of the $0^{\circ}, 90^{\circ}$ and $0^{\circ} / 90^{\circ}$ graphite-epoxy specimens are shown in Fig. 10 whereas the normal strain contours are depicted in Figs. 11 and 12 . In the test section of the specimens where the strain gages would be attached, the shear and normal strains are approximately uniform. Strain contours for $0^{\circ} / 90^{\circ}$ specimen have characteristics of both $0^{\circ}$ and $90^{\circ}$ specimens and its response is essentially the average of the response of the $0^{\circ}$ and $90^{\circ}$ specimens. 


\section{Fixture-to-specimen contact region}

In the $0^{\circ}$ specimen, $\varepsilon_{y}$ is largest at the inner most contact region and decreases radially from the innermost contact region into the test section, Fig. 11a. The $\varepsilon_{y}$ in the test section is about $16 \%$ of the $\varepsilon_{y}$ at the innermost contact region. As shown in Fig. 12a, $\varepsilon_{x}$ is small, about $14 \%$ of the $\varepsilon_{y}$, at the innermost contact region. Shear strain $\gamma_{x y}$ is similar in magnitude to $\varepsilon_{y}$. For the $90^{\circ}$ specimen, the largest $\varepsilon_{y}$ occurs at the two antisymmetric inner contact regions next to the notch root and only decreases vertically, Fig. 11b. In the test section, there is no presence of $\varepsilon_{y}$. The magnitude of $\varepsilon_{x}$ at the innermost contact region is compressive and is of the same magnitude as $\varepsilon_{\mathrm{y}}$ and $\gamma_{\mathrm{xy}}$. For $0^{\circ} / 90^{\circ}$ specimens, the longitudinal strain $\varepsilon_{x}$ contour is more representative of the strain contour of the $0^{\circ}$ specimen whereas the $\varepsilon_{y}$ contour is similar to that of $90^{\circ}$ specimen.

\section{Notch region}

Ideally, the specimen should fail in shear at the minimum cross section so that the notches should not provide any stress raising effect. Experimental observations $[7,15]$ indicate that the ideal condition is not achieved and that the failure locations for the $0^{\circ}$ and $90^{\circ}$ specimens are found at regions close to the intersection of the notch root and notch flank, see Fig. 2b, rather than at the minimum cross section. The linear elastic finite element results obtained here indicate that a complex strain state occurs in the region where initial failure is generally observed. At the intersection of the notch root and flank the transverse normal strain, $\varepsilon_{y}$, is tensile with a value of approximately $24 \%$, see Figs. 10a and 11a, of the largest shear strain $\gamma_{x y}$ in the test section, and the shear strain $\gamma_{x y}$ at the notch root-flank intersection is approximately $74 \%$ of the largest shear strain in the test section, for the $0^{\circ}$ graphite-epoxy specimen.

In the case of the $90^{\circ}$ specimen, Fig. $12 \mathrm{~b}$, the longitudinal strain $\varepsilon_{\mathrm{x}}$ is tensile, at the notch root-flank intersections further from the applied loading (point $\mathbf{x}$ in Fig. 12b), with a value of approximately $18 \%$ of the shear strain $\gamma_{x y}$ at the center of the test section. The corresponding shear strain at the notch root-flank intersection is about $51 \%$ of the $\gamma_{x y}$ at the center of the test section.

It is beyond the scope of this linear elastic analysis to estimate the failure mode or strength of the Iosipescu specimens because of the significant nonlinear material and geometric effects that occur. However, this analysis will provide insight into failure 
location and some of the important material and geometrical parameters that control the response of the specimen. The results from the finite element analysis indicate mixed mode failures are feasible in the notch root-flank region. This is supported by experiments $[7,15]$ which indicate that the notch root-flank intersections are critical regions where failures are frequently initiated. Therefore, the use of the $0^{\circ}$ and $90^{\circ}$ Iosipescu specimens to measure shear strengths is ill-advised because the strength is not solely a function of the shear properties of the material. An additional complexity occurs for the $90^{\circ}$ and $0^{\circ} / 90^{\circ}$ specimens, that is the specimens twist [7] which produces mixed mode failures.

\section{Correction Factor}

The shear strain between notch tips is not constant for the different ply orientations and materials evaluated, see Figs. $13 \mathrm{a}-13 \mathrm{c}$. If a shear modulus $\mathrm{G}_{12}$ were calculated using the experimentally measured shear strain (using strain gages), erroneous results would be obtained. To account for the nonuniformity of shear strain distribution in shear modulus calculation, correction factors are developed. Correction factors are obtained by dividing the shear strains, $\gamma_{g a g e}$, at the center of the test section of the specimen by the average

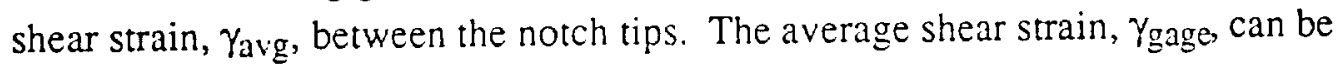
analytically determined by averaging the shear strain over an area that would be covered by a strain gage. The correction factor and correct shear modulus are calculated by

$$
\begin{aligned}
\gamma_{\text {avg }} & =\frac{1}{h} \int_{\frac{h}{2}}^{\frac{h}{2}} \gamma_{x y} d y \\
C F & =\frac{\gamma_{\text {gage }}}{\gamma_{\text {avg }}} \\
G_{x y} & =\frac{\tau_{\text {avg }}}{\gamma_{\text {avg }}}=\frac{\tau_{\text {avg }}}{\gamma_{\text {gage }}} \times C F=C F \times G^{*}
\end{aligned}
$$

where $h$ is the distance between two notch tips and $G^{*}$ is the apparent shear modulus ( $\tau_{\text {avg }} / \gamma_{\text {gage }}$ ). A comparison of shear strain distributions along the notch axis normalized with respect to the average shear strains for $0^{\circ}, 90^{\circ}$ and $0^{\circ} / 90^{\circ}$ graphite-epoxy, Kevlarepoxy and glass-epoxy specimens is shown in Fig. 13. The corresponding correction 
factors are shown in Fig. 13 and depend on the material orthotropic ratios. For the $0^{\circ}$ specimen, the correction factor is less than 1.0. The larger the material orthotropic ratio, the smaller the correction factor. For $90^{\circ}$ specimens, the reverse trends were observed. Approximately, the correction factors can be expressed as,

$$
C F=1.036-0.125 \times \log \left(\frac{E_{x}}{E_{y}}\right)
$$

where $E_{x}$ and $E_{y}$ are extensional stiffnesses in the longitudinal and transverse directions, respectively. Figure 14 is a plot of the correction factors as a function of material orthotropic ratio. Note that for the $0^{\circ} / 90^{\circ}$ specimens, which have unit orthotropic ratio, the shear strain distributions are more uniform in the gage section. In the calculation of shear modulus, however, a correction factor is still necessary. The correction factor for the $0^{\circ} / 90^{\circ}$ specimens is approximately the average of the correction factors of the $0^{\circ}$ and $90^{\circ}$ specimens. Note that the correction factors depend on the material orthotropic ratios and are insensitive to the shear moduli to be measured. In Fig. 15, it is shown that increasing or decreasing the shear modulus of the $0^{\circ}$ graphite-epoxy [20] specimen by 40 percent, the corresponding correction factors decrease or increase 1.3 and 2.0 percent, respectively. The same insensitivity of the correction factors to shear moduli for $90^{\circ}$ and $0^{\circ} / 90^{\circ}$ specimens is also shown in Fig. 15.

\section{$\underline{\text { Simulated Gage Readings }}$}

Sullivan [14] stated that "In a properly loaded Iosipescu specimen, the two strains at $\pm 45 \mathrm{deg}$ should be equal in magnitude and opposite in sign to a reasonable approximation." Morton et al. [7] and Lee and Munro [18] showed recently that this condition cannot be achieved experimentally for $0^{\circ}$ specimens. Lee and Munro tried to achieve Sullivan's condition by adding shims to the specimen and having the fixture contact surface carefully ground, but the effort proved to be of no effect. The inequality of strains in the $\pm 45^{\circ}$ gages can be attributed to the presence of transverse normal strains in the gage section and is an inherent property for $0^{\circ}$ specimen. The simulated individual gage readings for $0^{\circ}, 90^{\circ}$ and $0^{\circ} / 90^{\circ}$ graphite-epoxy specimens are shown in Fig. 16. The magnitude of the predicted strains in the simulated $\pm 45^{\circ}$ gages are approximately equal for $90^{\circ}$ and $0^{\circ} / 90^{\circ}$ specimens, see Fig. 16. However, for the $0^{\circ}$ specimens, the strain recorded by the $+45^{\circ}$ gage is larger in magnitude than the strain measured by the $-45^{\circ}$ 
gage. The absolute value of the ratio of tensile to compressive strain, as determined from the $\pm 45^{\circ}$ gages, is 0.6 for graphite-epoxy and 0.8 for Kevlar and glass-epoxy specimens.

Even though the $\pm 45^{\circ}$ gages in the $0^{\circ}$ specimen do not measure strains of equal magnitude, the shear strain calculation is still valid provided strains in the test section are constant. The strains measured by the gages can be expressed in terms of strains in the specimen coordinate system $(x, y)$,

$$
\begin{aligned}
& \text { SG } 1=0.5\left(\gamma_{x y}^{45}+\varepsilon_{x}{ }^{45}+\varepsilon_{y}^{45}\right) \\
& \text { SG } 2=0.5\left(-\gamma_{x y}^{-45}+\varepsilon_{x}{ }^{-45}+\varepsilon_{y}^{-45}\right) \\
& \gamma_{12}=\operatorname{SG} 1-\operatorname{SG} 2=0.5\left(\gamma_{x y}^{45}+\gamma_{x y}^{45}+\varepsilon_{x}^{45}-\varepsilon_{x^{-45}}+\varepsilon_{y}^{45}-\varepsilon_{y}^{-45}\right)
\end{aligned}
$$

where SG's represent strain gage readings, as shown in Fig. 2, and $\gamma_{x y}, \varepsilon_{x}$ and $\varepsilon_{y}$ represent shear strain, longitudinal and transverse normal strains averaged over the gage length with superscripts \pm 45 indicating the gage directions. Under pure shear, the normal strains are zero and the shear strain can be obtained by

$$
\gamma_{12}=\mathrm{SG} 1-\mathrm{SG} 2=0.5\left(\gamma_{\mathbf{x y}}^{45}+\gamma_{\mathbf{x y}}^{45}\right) .
$$

For $90^{\circ}$ and $0^{\circ} / 90^{\circ}$ specimens, the normal strains $\left(\varepsilon_{\mathrm{x}}{ }^{45}, \varepsilon_{\mathrm{y}}{ }^{45}, \varepsilon_{\mathrm{x}}{ }^{-45}\right.$ and $\left.\varepsilon_{\mathrm{y}}{ }^{-45}\right)$ in the gage regions are negligible and equation (7) reduces to equation (8). However, for the $0^{\circ}$ specimens, the longitudinal normal strain, $\varepsilon_{\mathrm{x}}$, is negligible but the transverse normal strain, $\varepsilon_{y}$, is significant, about $9.5 \%$ and $24.4 \%$ of $\gamma_{\text {avg }}$ for Kevlar-epoxy and graphiteepoxy, respectively; therefore SG1 and SG2 would not measure equal and opposite strains. However, if the transverse normal strain distribution is uniform in the region where the strain gages are located, the influence of the transverse normal strain field on the two gages is the same even when separate strain gage rosettes are used and the calculation of the shear strain would reduce to equation (8). That is, if the transverse normal strain field is uniform in the gage section, the shear strain calculated from the two gage readings in the $0^{\circ}$ specimen is a valid shear strain and can be used in calculating the shear modulus. Lee and Munro's suggestion [18] that the $0^{\circ}$ specimen should not be used for measurement of the in-plane shear properties does not appear to be correct, if it is based solely on the inequality of the $\pm 45^{\circ}$ strain gage readings. 


\section{Load-Point Effect}

The W2 fixture distinguishes itself from the antisymmetric four-point-bend method by application of uniform displacement over a large section of the specimen edge and thus avoids the problem of local crushing resulting from concentrated loads. One consequence of using the W2 fixture is the region of load introduction is a function of the applied load and specimen ply orientation. Employing the proposed analysis method the load distribution varies as a function of applied load. For small applied loads the load distribution is near uniform whereas for applied loads where large deformations occur the load distribution would approach the concentrated load case. For illustration purposes, a uniformly distributed load and a concentrated load case is used to demonstrate their effects on shear strain distribution, Fig. 17. Though these two load cases may be extreme the results depicted in Figs. 18-20 show that location of the load points has a profound effect upon the shear strain distribution along the notch axis for the $0^{\circ}$ specimen. For graphite-epoxy, the deviation of shear modulus correction factors from the model in Fig. 6 a could be as large as $10 \%$. The deviation may be as large as $7 \%$ and $5 \%$ for glassepoxy and Kevlar-epoxy respectively. But for the $90^{\circ}$ specimen, the load-point effect is negligible for graphite-epoxy and is as low as $2 \%$ for Kevlar-epoxy and glass-epoxy for these two load models. Hence it is possible that the shear modulus obtained experimentally from $0^{\circ}$ specimens will have large variations.

The W2 fixture has load points which are farther away from the notch axis as compared to those of the W1 fixture, and the induced transverse normal strains in the gage section for the $0^{\circ}$ specimen are smaller. Hence it might be suggested that if the fixture were redesigned such that the load points were even farther away from the notch axis, a better shear distribution might be obtained along the notch axis for the $0^{\circ}$ specimen. However, to obtain shear force $P$ in the test section, the equivalent concentrated load, as shown in Fig. 17a, is $\mathrm{Pa} /(\mathrm{a}-\mathrm{b})$ and $\mathrm{Pb} /(\mathrm{a}-\mathrm{b})$ for the inner and outer load pairs, respectively. If the load points are located as shown in Fig. $17 \mathrm{~b}$, where $b$ is large, the equivalent concentrated forces for the inner force couple are about twice the magnitude of those in Fig. 17a and the equivalent concentrated forces for the outer force couple are about six times larger in magnitude than those in Fig. 17a. Thus if the load points are too far away, the concentrated forces would become so large that local crushing of the specimen may occur. It is shown earlier that the transverse normal strain in the test section for the $0^{\circ}$ specimen would not affect the calculation of shear modulus 
because the distribution of transverse normal strain is uniform in the gage section. So, even a redesigned W2 fixture will not provide pure shear in the test section, it is not necessary to move the loading faces of the fixture farther away from notch axis.

\section{CONCLUSIONS}

Linear finite element analyses of Iosipescu specimen tested in modified Wyoming fixture have been performed and evaluated. It is suggested that contact length between the specimen and fixture, constraint type and compatibility should be considered in the finite element modeling. To better model the fixture-specimen kinematics, an iterative analysis procedure was applied. It was found that the finite element modeling was not affected by the material systems (such as graphite-, Kevlar- and glass-epoxy) but are influenced by the elastic stiffness due to different fiber orientation $\left(0^{\circ}, 90^{\circ}\right.$ and $\left.0^{\circ} / 90^{\circ}\right)$ producing different deformation of the specimen in the fixture. For the $0^{\circ}$ specimen, it is shown that the pure shear state in the test section was not achievable. However, the shear strain calculation is not affected by the uniformity of normal strain distributions. It is shown that correction factors are needed for the calculation of shear modulus and that the correction factor for the $0^{\circ}$ specimen is strongly dependent on the finite element model used, but not for $90^{\circ}$ specimen.

\section{ACKNOWLEDGEMENTS}

This work has been supported by U.S. Army Aerostructures Directorate under NASA Langley Research Center Research Grant NAG-1-1053. 


\section{References}

1. Rosen, B.W., "A Simple Procedure for Experimental Determination of the Longitudinal Shear Modulus of Unidirectional Composites," Journal of Composite Materials, $6: 552-554$ (1972).

2. Pindera, M. J. and Herakovich, C. T., "Shear Characterization of Unidirectional Composites with the Off-Axis Tension Test," Experimental Mechanics, 26 (1) : 103112 (1986).

3. Whitney, J. M., Stansbarger, D. L. and Howell, H. B., "Analysis of the Rail Shear Test-Application and Limitations," Jolurnal of Composite Materials, 5 : 24-34 (1971).

4. Walrath, D.E. and Adams, D. F., "The Iosipescu Shear Test as Applied to Composite Materials," Experimental Mechanics, 23 (1) : 105-110 (1983).

5. Swanson, S. R., Messick, M. and Toombes, G. R., "Comparison of Torsional Tube and Iosipescu In-plane Shear Test Results for a Carbon Fiber-Reinforced Epoxy Composite," Composites, 2 (3) : 220-224 (1985).

6. Adams, D. F. and Walrath, D. E.,"Further Development of the Iosipescu Shear Test Method,"Experimental Mechanics : 27 (2):113-119 (1987).

7. Morton, J., Ho, H., Tsai, M.Y. and Farley, G.L., " An Evaluation of the Iosipescu Specimen for Composite Materials Shear Property Measurement," Journal of Composite Materials, 26 (5) : 708-750 (1992).

8. Walrath, D.E. and Adams, D. F., "Analysis of the Stress State in an Iosipescu Shear Test Specimen," Report UWME-DR-301-101-1, Deparment of Mechanical Engineering, University of Wyoming, (June 1983).

9. Sullivan, J. L.,Kao, B.G. and Van Oene, H.,"Shear Properties and a Stress Analysis Obtained from Vinyl-ester Iosipescu Specimen," Experimental Mechanics, 24 (3): 223-232 (1984).

10. Adams, D. F. and Walrath, D. E.,"Current Status of the Iosipescu Shear Test Method,"Journal of Composite Materials, 21: 494-507 (1987).

11. Pindera, M. J., Choksi, G., Hidde, J. S. and Herakovich, C. T.,"A Methodology for Accurate Shear Characterization of Unidirectional Composites," Journal of Composite Materials, 21: 1164-1184 (1987).

12. Kumosa, M. and Hull, D., "FEM Analysis of Mixed Mode Fracture in the Iosipescu Shear Test," Proceedings of the Sixth International Conference On Composite Materials/Second European Conference on Composite Materials, Elsevier Applied Science, Matthews, F. L., Buskell, N. R. C., Hodgkinson, J. M. and Morton, J., Eds., Vol. 3, pp. 243-253 (1987).

13. Barnes, J. A., Kumosa, M. and Hull, D., "Theoretical and Experimental Evaluation of the losipescu Shear Test," Composites Science and Technology, $28: 251-268$ (1987). 
14. Sullivan, J. L., "The Use of losipescu Specimens," Experimental Mechanics, 28 (3) : 326-328 (1988).

15. Abdallah, M. G. and Gascoigne, H. E., "The Influence of Test Fixture Design of Iosipescu Shear Test for Fiber Composite Material," Test Methods for Design Allowables for Fibrous Composites: 2nd Vol., ASTM STP 1003 : 231-260, C. C. Chamis, Ed., American Society for Testing and Materials, Philadelphia, Pennsylvania (1989).

16. Pindera, M. J., Ifju. P. and Post, D., "Iosipescu Shear Characterization of Polymeric and Metal Marrix Composites," Experimental Mechanics, 30 (1) : 101-108 (1990).

17. Wilson, D.W.,"Evaluation of the V-notched Beam Shear Test Through an Interlaboratory Study", Journal of Composite Technology and Research, 12 (3): $131-138$ (1990).

18. Lee, S. and Munro, M., "Evaluation of Testing Techniques for the Iosipescu Shear Test for Advanced Composite Materials," Journal of Composite Materials, 24 : 419-440 (1990).

19. Lee, S., Munro, M. and Scott, R.F.,"Evaluation of Three In-plane Shear Test Methods for Advanced Composite Materials, "Composites, 21 (6) : 495-502 (1990).

20. Tsai, S. W. , "Composite Design," 4th edition, Appendix B, p B-2, Think Composits, Dayton, Ohio (1988). 


\section{Figure Captions}

Fig. 1. Original Iosipescu (a) and (b) shear fixture and (c) specimen.

Fig. 2 Modified Iosipescu shear (a) fixture and (b) specimen.

Fig. 3. Deformation characteristics of Iosipescu shear specimen.

Fig. 4. Finite element model of Iosipescu specimen.

Fig. 5. Initial displacement (applied and constrained) distribution on Iosipescu specimen.

Fig. 6. Distributed loads on the specimen sides due to imposition of uniform displacement for (a) $0^{\circ}$, (b) $90^{\circ}$, (c) $0^{\circ} / 90^{\circ}$ specimens.

Fig. 7. Normal and shear strains at $x=0$, normalized with respect to average shear strain, for (a) graphite-epoxy, (b) Kevlar-epoxy, (c) glass-epoxy $0^{\circ}$ specimen.

Fig. 8. Normal and shear strains at $x=0$, normalized with respect to average shear strain, for (a) graphite-epoxy, (b) Kevlar-epoxy, (c) glass-epoxy $90^{\circ}$ specimen.

Fig. 9. Normal and shear strains at $x=0$, normalized with respect to average shear strain, for (a) graphite-epoxy,(b) Kevlar-epoxy, (c) glass-epoxy $0^{\circ} / 90^{\circ}$ specimen.

Fig. 10. Typical shear strain contours for (a) $0^{\circ}$, (b) $90^{\circ}$, (c) $0^{\circ} / 90^{\circ}$ graphite-epoxy Iosipescu specimen.

Fig. 11. Transverse normal strain contours for (a) $0^{\circ}$, (b) $90^{\circ}$ graphite-epoxy Iosipescu specimen.

Fig. 12. Longitudinal normal strain contours for (a) $0^{\circ}$, (b) $90^{\circ}$ graphite-epoxy Iosipescu specimen.

Fig. 13. Shear strain distribution at $\mathrm{x}=0$ for (a) $0^{\circ}$, (b) $90^{\circ}$ graphite-epoxy, Kevlar-epoxy and glass-epoxy specimens.

Fig. 14. Correction factor vs.material orthotropic ratio.

Fig. 15. Sensitivity of the correction factors to shear moduli for graphite-epoxy Iosipescu specimen.

Fig. 16. Normalized strains of $\pm 45^{\circ}$ gages from finite element analysis for (a) $0^{\circ}$, (b) $90^{\circ}$, (c) $0^{\circ} / 90^{\circ}$ graphite-epoxy losipescu specimen.

Fig. 17. Force couple finite element models of Iosipescu specimen tested in Wyoming fixture, (a)concentrated load model, (b) distributed load model.

Fig. 18. Load point effect on the shear strain distribution at $x=0$ for (a) graphite-epoxy, (b) Kevlar-epoxy, (c) glass-epoxy $0^{\circ}$ specimen.

Fig. 19. Load point effect on the shear strain distribution at $x=0$ for (a) graphite-epoxy,

(b) Kevlar-epoxy, (c) glass-epoxy $90^{\circ}$ specimen. 
Fig. 20. Load point effect on the shear strain distribution at $x=0$ for (a) graphite-epoxy, (b) Kevlar-epoxy, (c) glass-epoxy $0^{\circ} / 90^{\circ}$ specimen. 


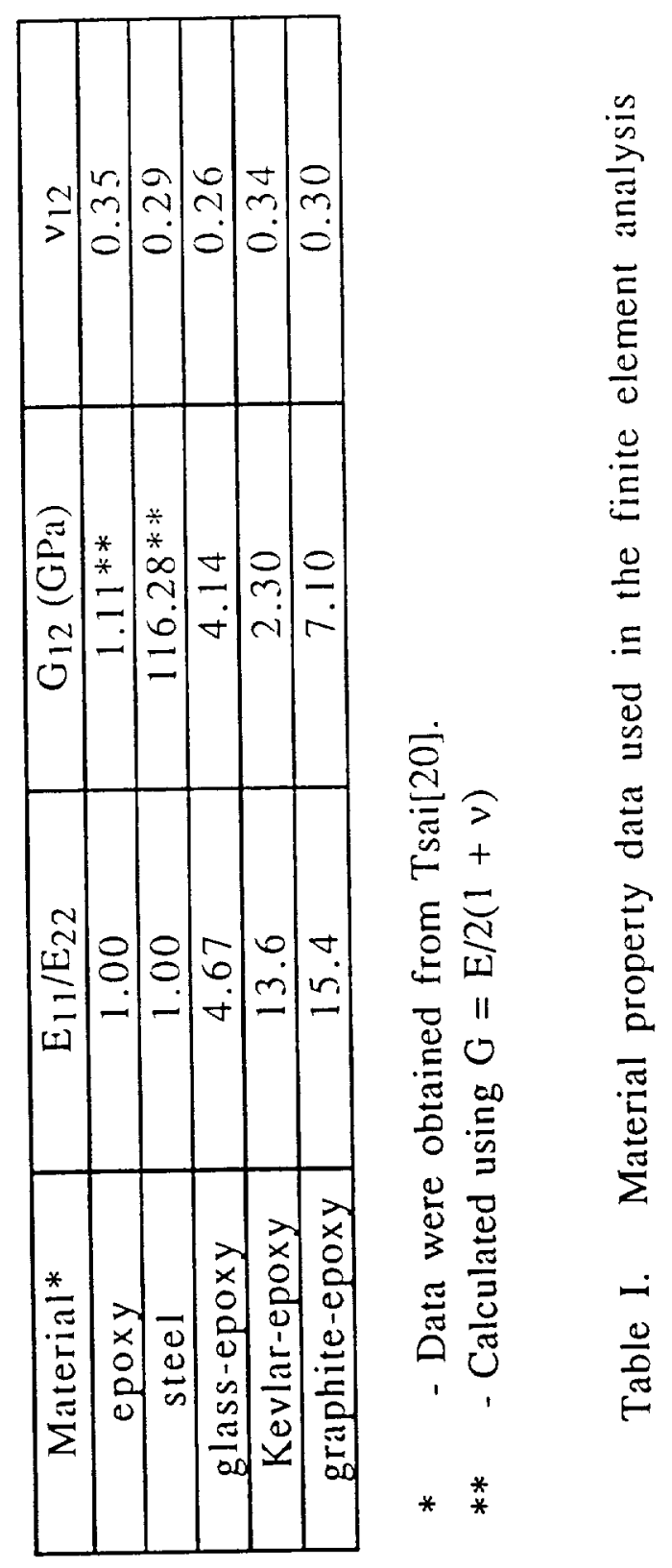




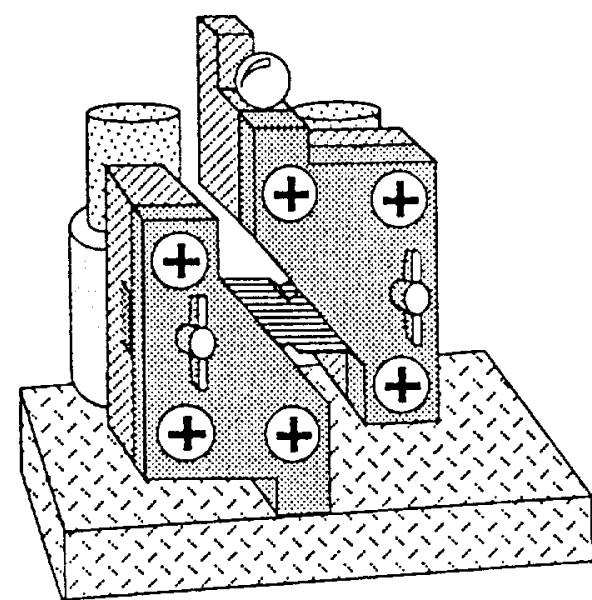

(a)

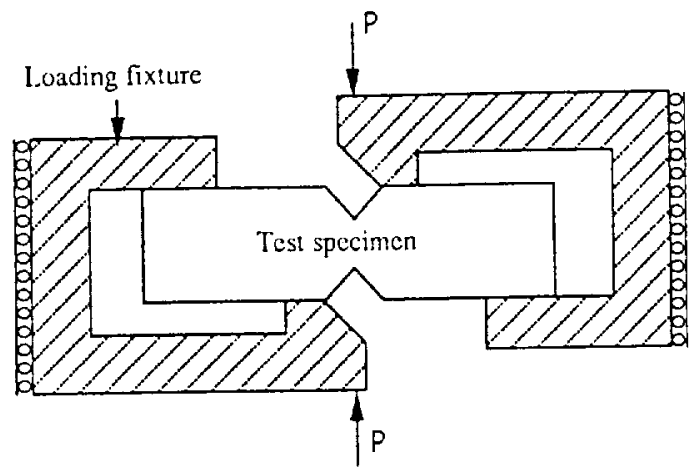

(b)

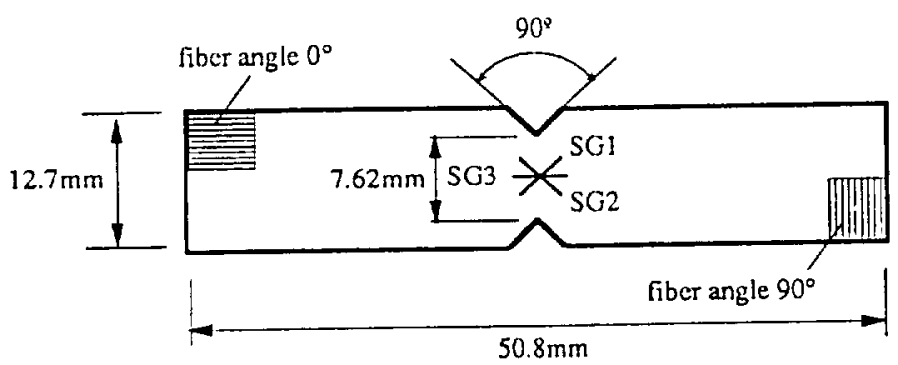

(c)

Fig. 1. Original Iosipescu (a) and (b) shear fixture and (c) specimen. 


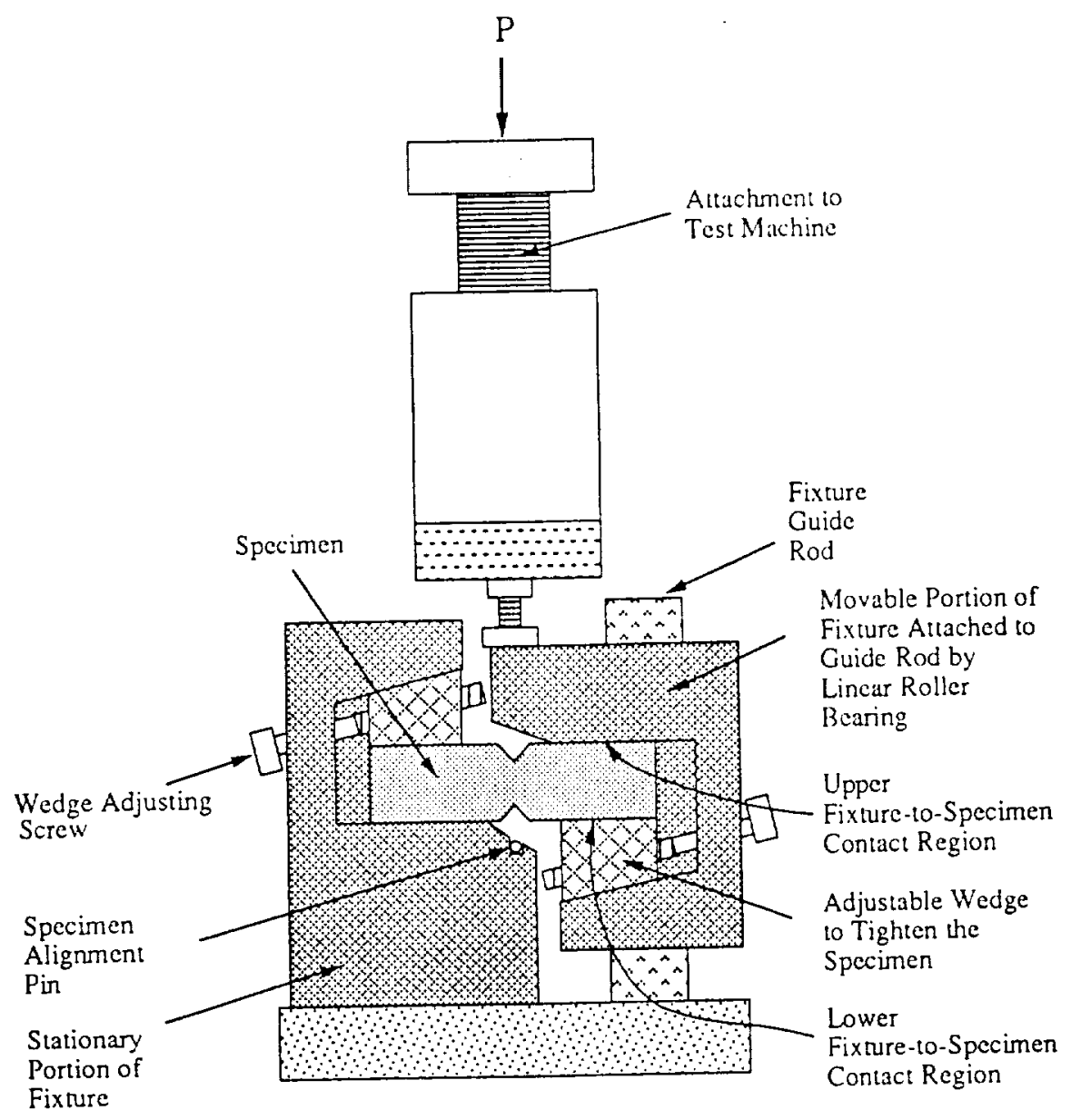

(a)

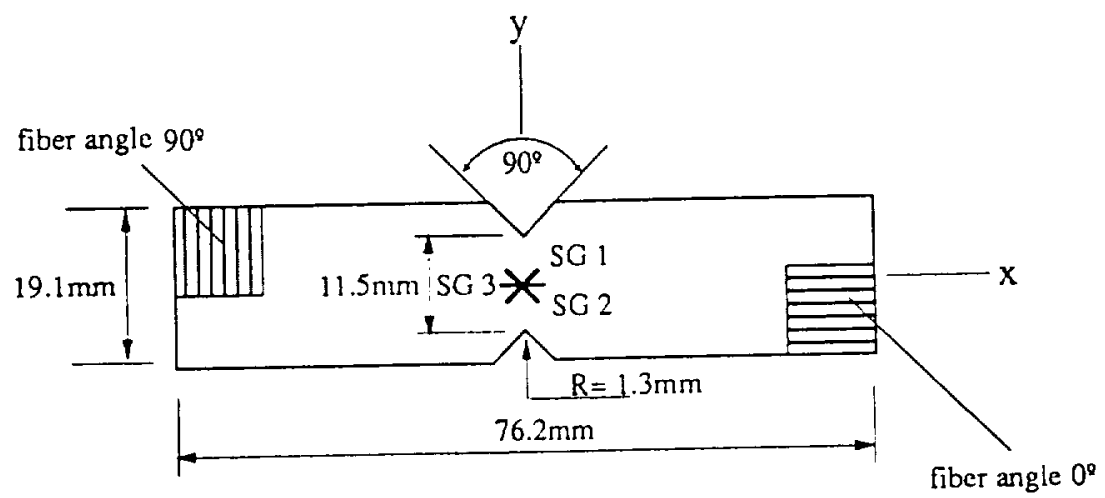

(b)

Fig. 2. Modified Iosipescu shear (a) fixture, (b) specimen. 


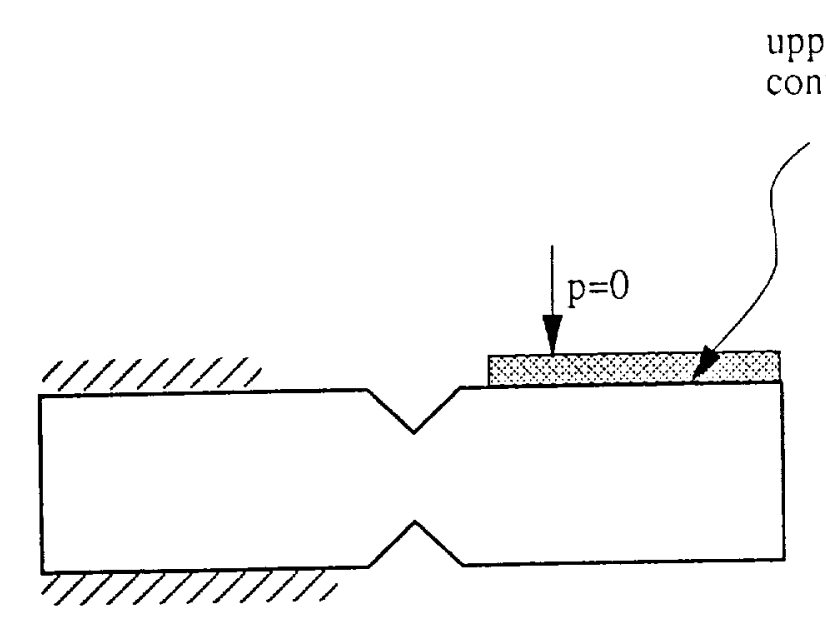

upper fixture-to-specimen

contact region

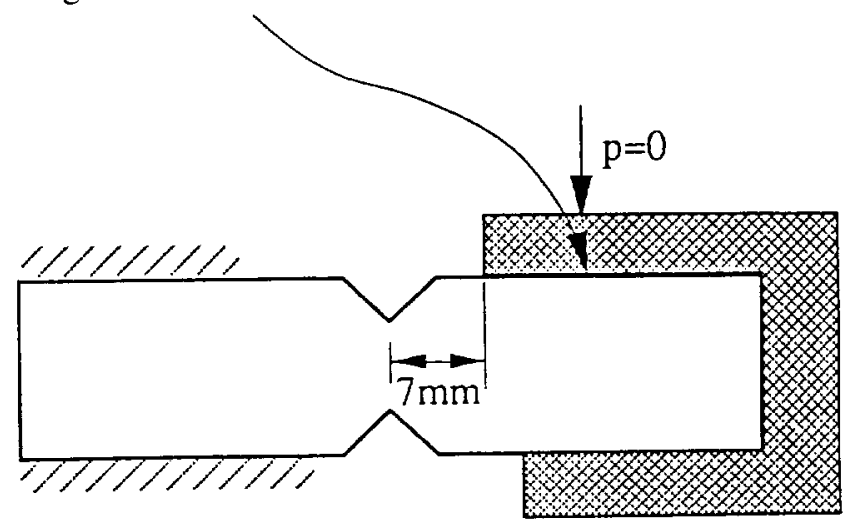

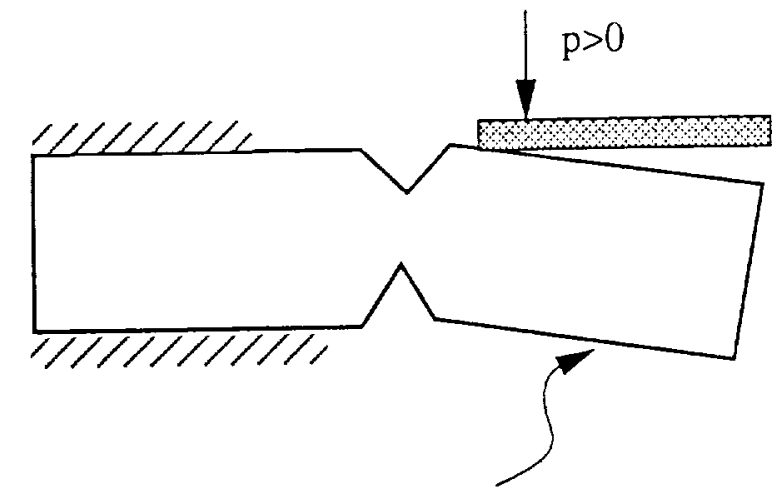

No reaction force along edge resulting in rotation of specimen causing a separation between fixture and specimen. (a) Iosipescu specimen without lower fixture-to-specimen contact region local in-plane bending

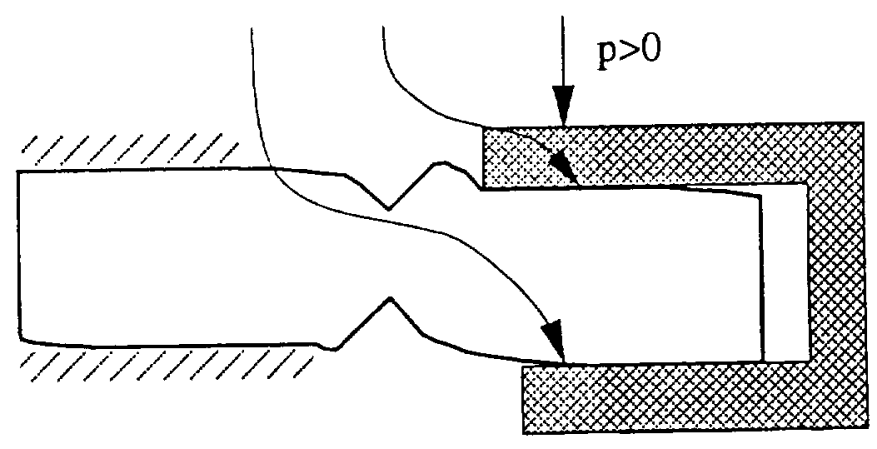

Reaction force developed along edge preventing the rotation of specimen

(b) Modified Iosipescu shear specimen

Fig. 3. Deformation Characteristics of Iosipescu shear specimen 


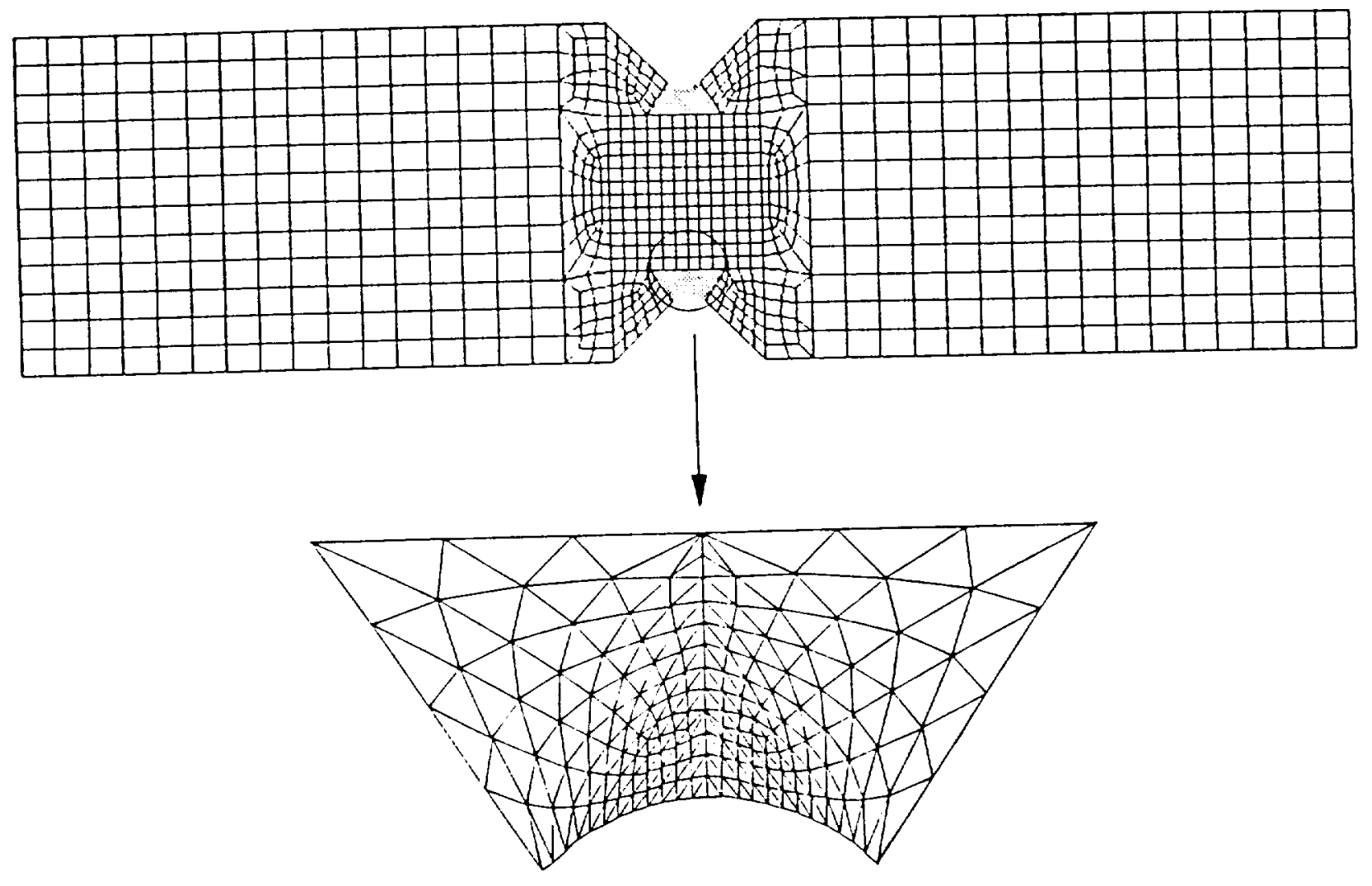

Fig. 4. Finite element model of Iosipescu specimen. 


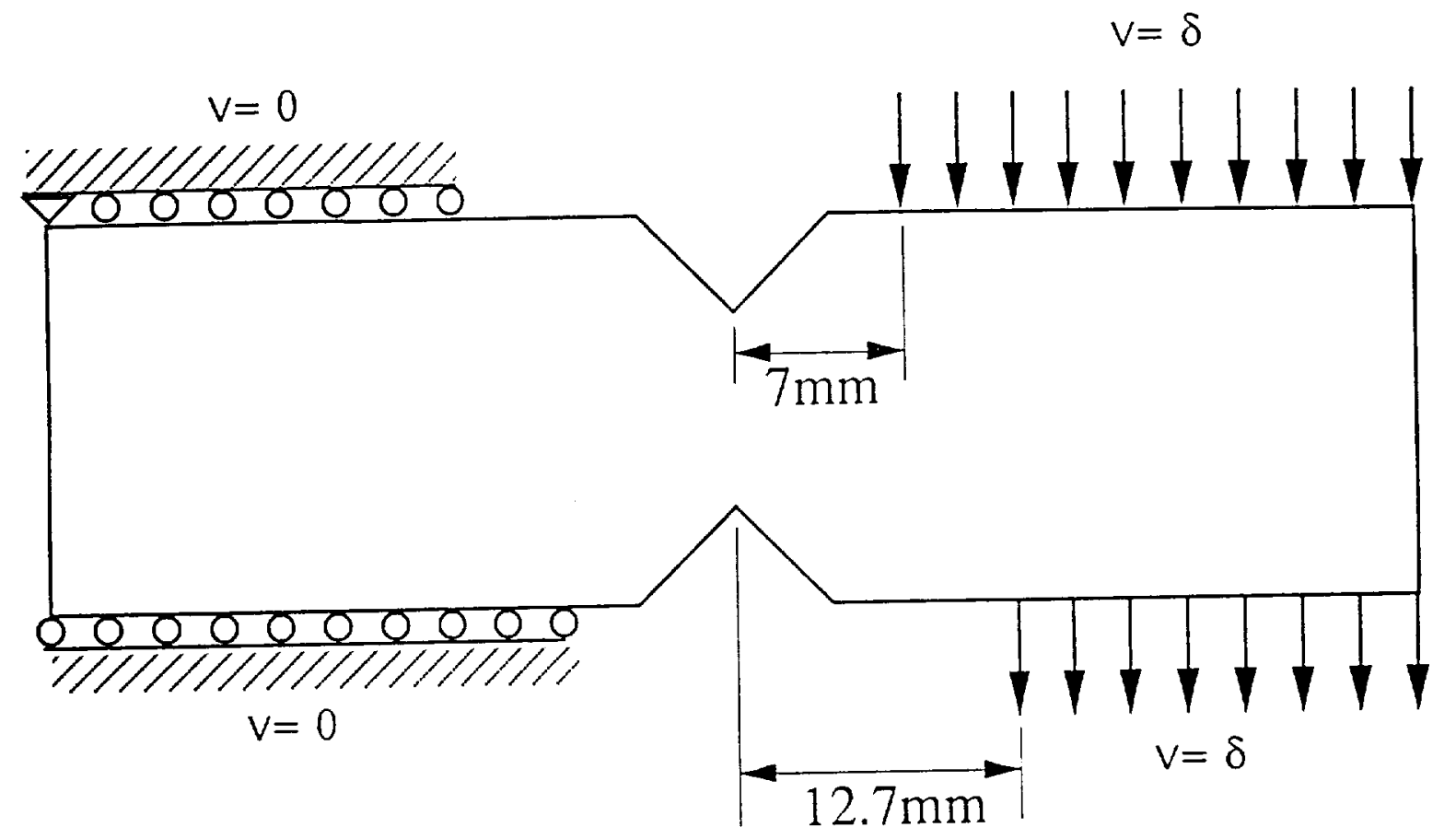

Fig. 5. Initial displacement (applied and constrained) distribution on losipescu specimen. 


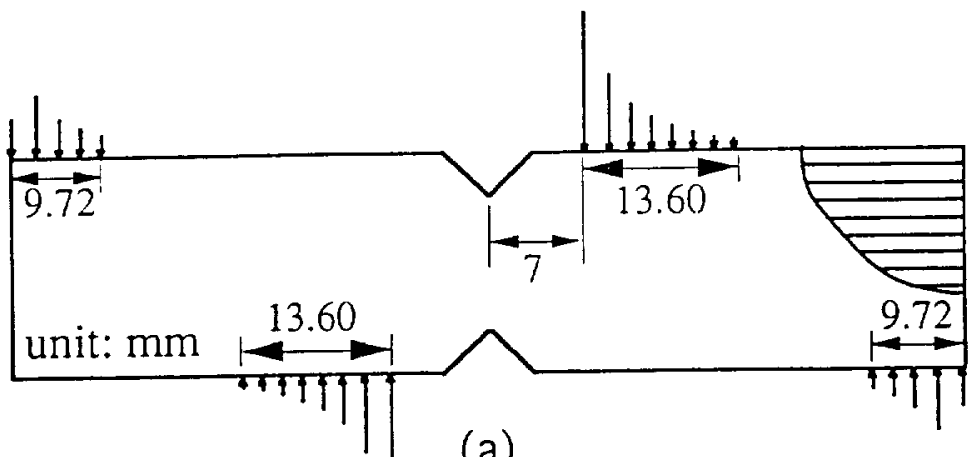

(a)
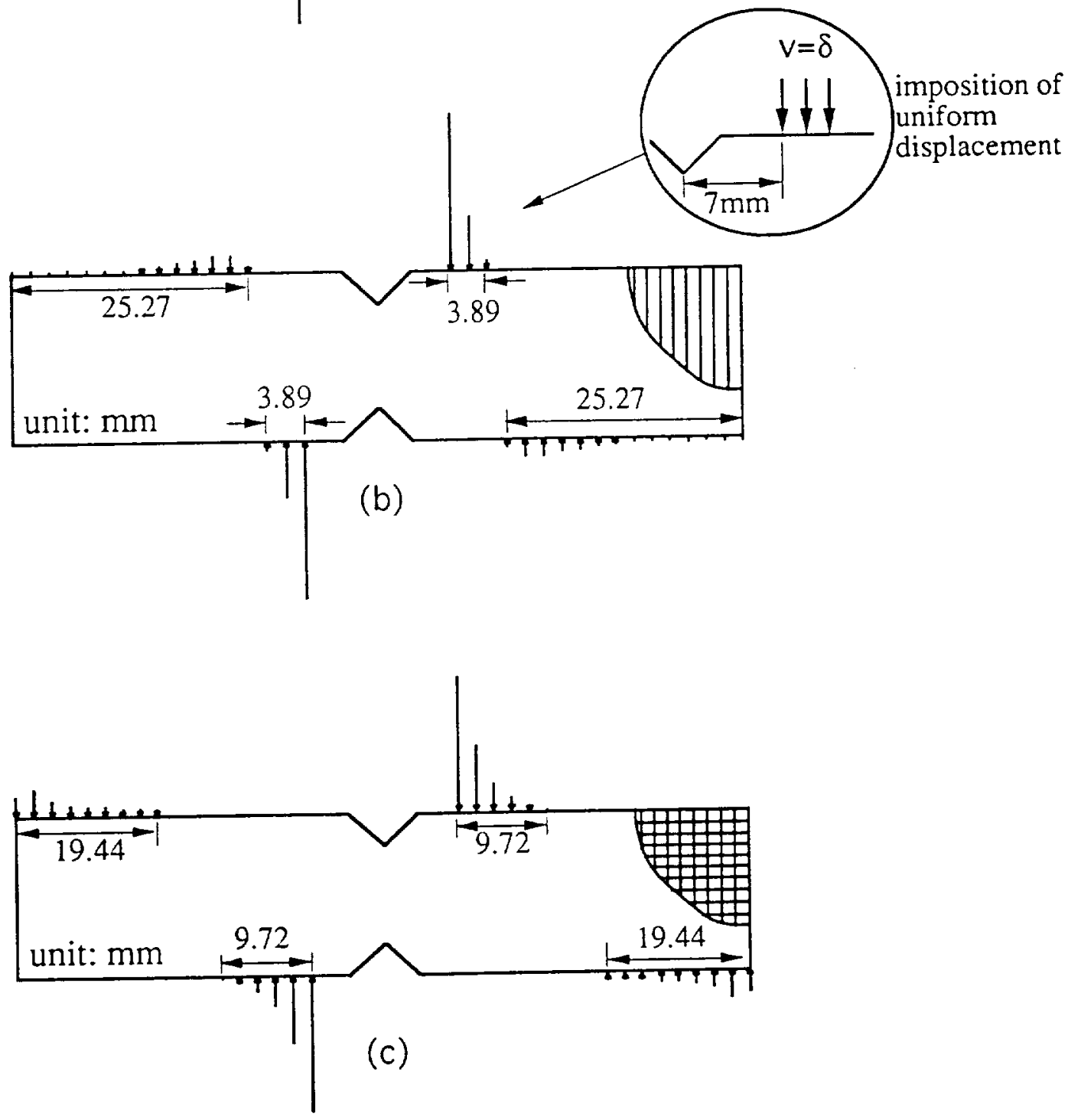

Fig. 6. Distributed loads on the specimen sides due to imposition of uniform displacement for (a) $0^{\circ}$, (b) $90^{\circ}$, (c) $0^{\circ} / 90^{\circ}$ specimens. 


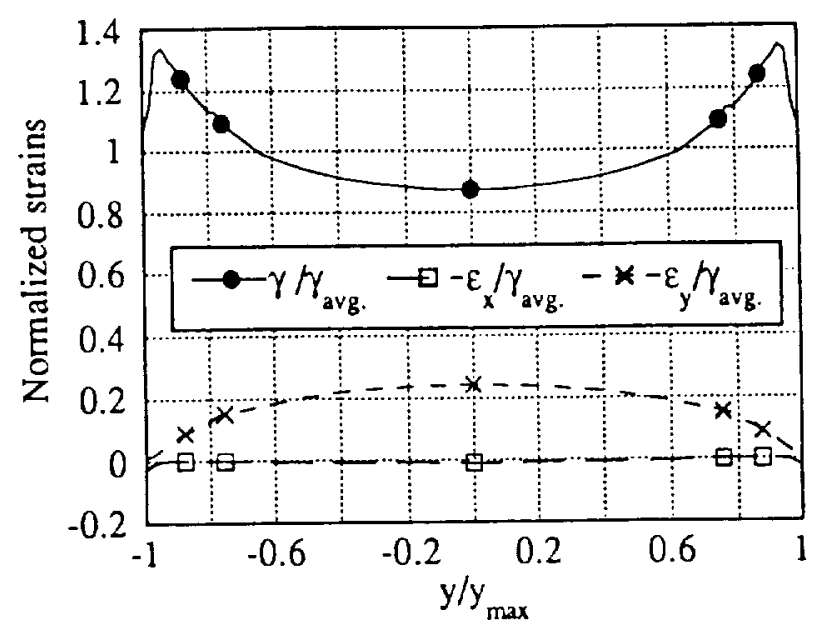

(a)

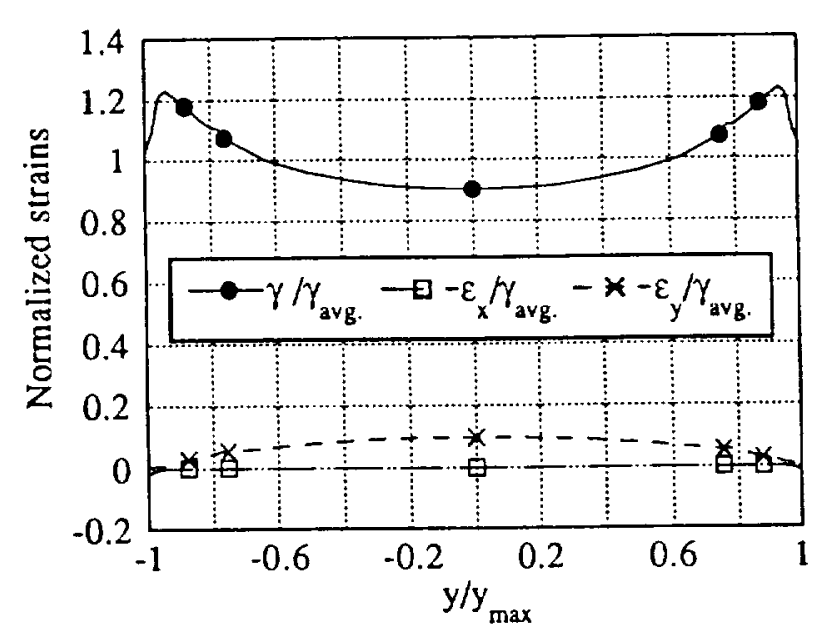

(b)

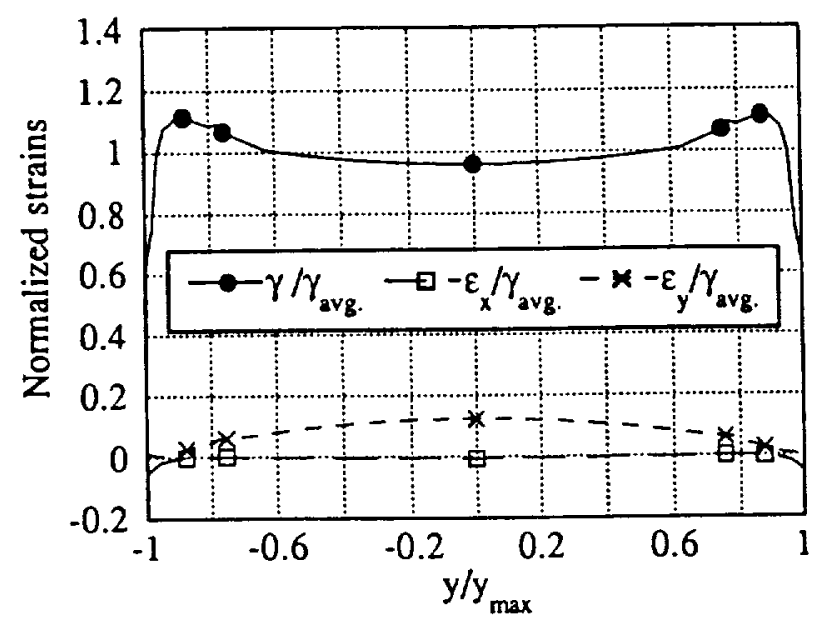

(c)

Fig. 7. Normal and shear strains at $x=0$, normalized with respect to average shear strain, for (a) graphite-epoxy, (b) Kevlar-epoxy, (c) glass-epoxy $0^{\circ}$ specimen. 


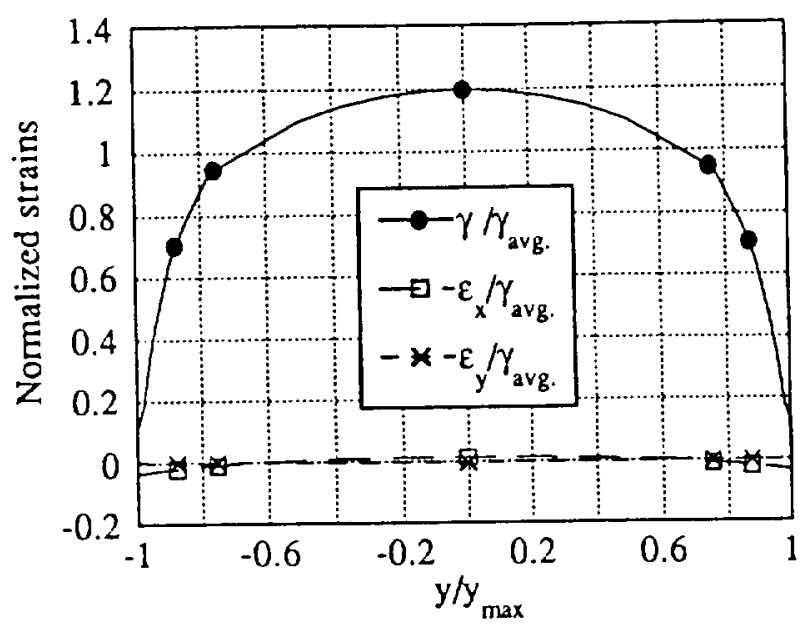

(a)

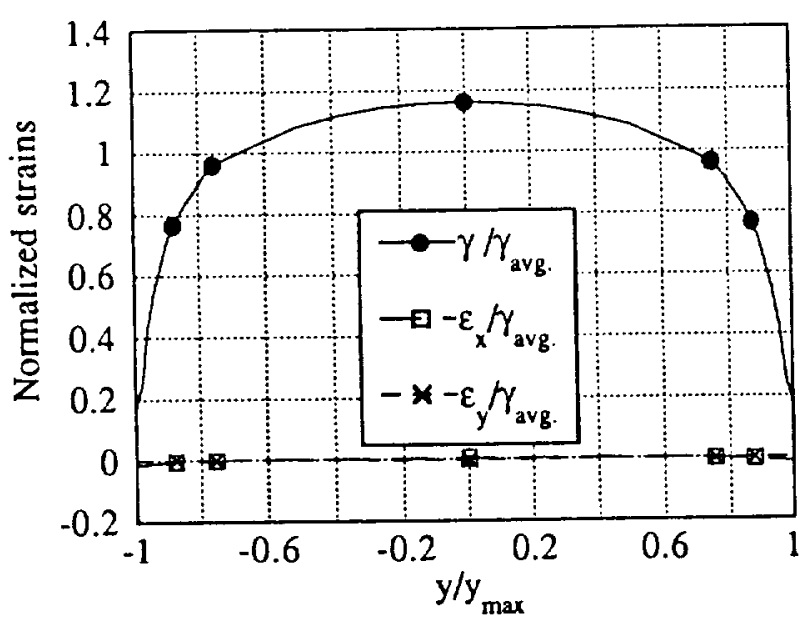

(b)

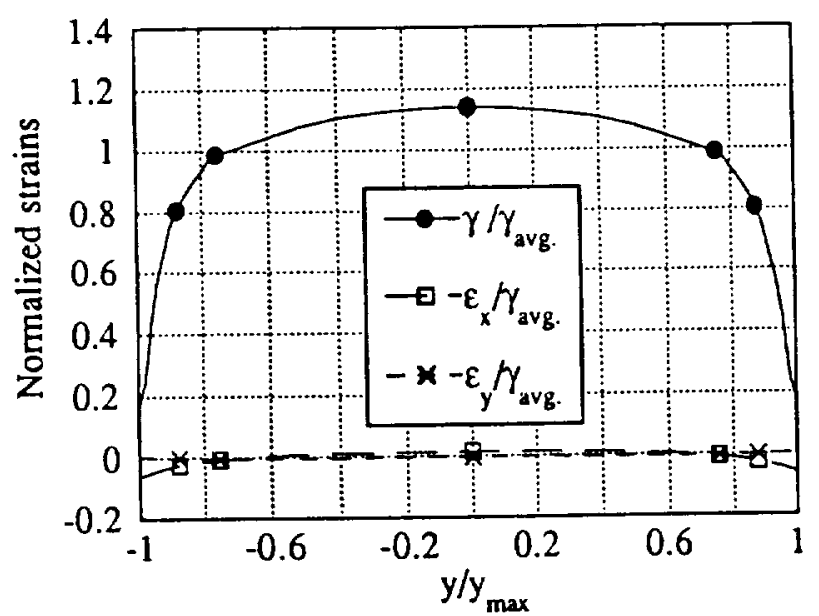

(c)

Fig. 8. Normal and shear strains at $x=0$, normalized with respect to average shear strain, for (a) graphite-epoxy, (b) Kevlar-epoxy, (c) glass-epoxy $90^{\circ}$ specimen. 


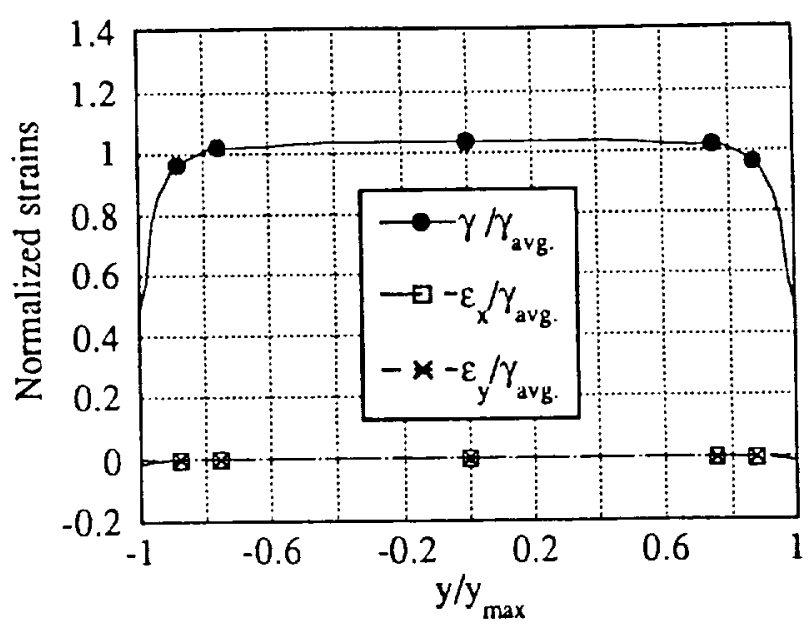

(a)

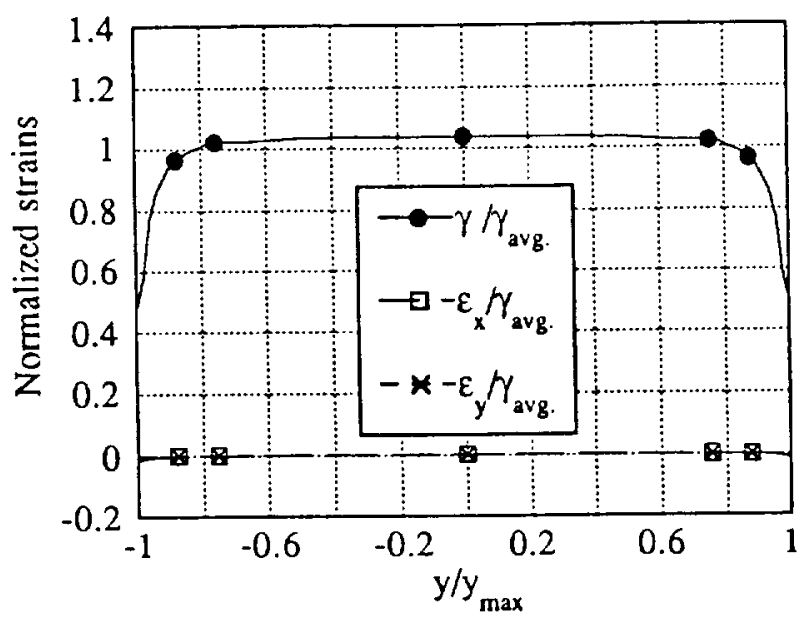

(b)

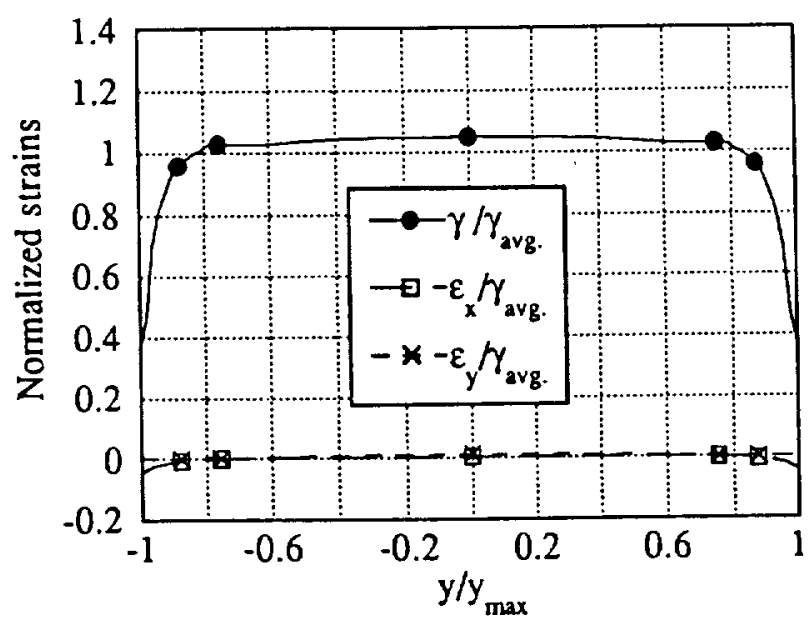

(c)

Fig. 9. Normal and shear strains at $x=0$, normalized with respect to average shear strain, for (a) graphite-epoxy,(b) Kevlar-epoxy, (c) glass-epoxy $0^{\circ} / 90^{\circ}$ specimen. 


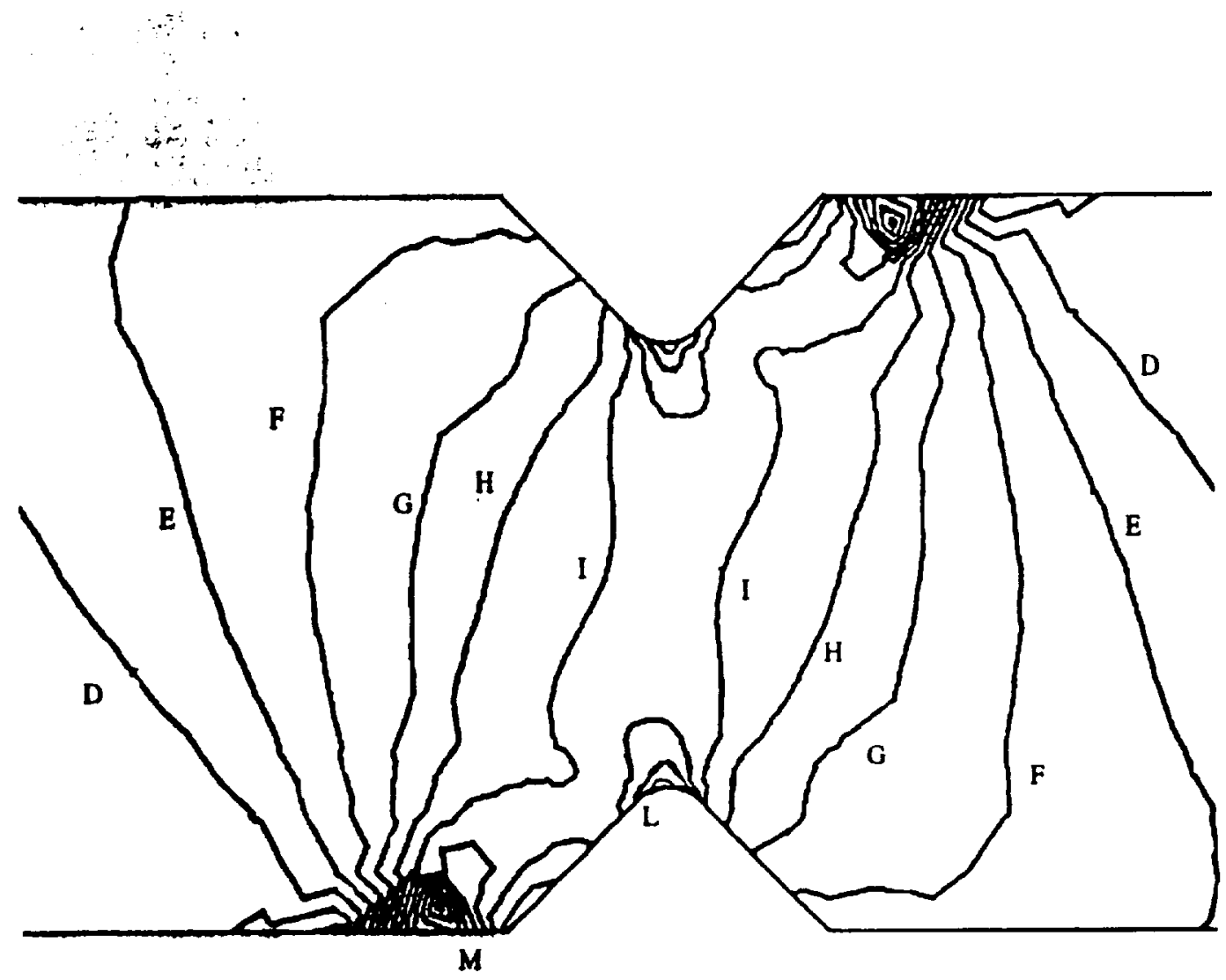

\begin{tabular}{|c|c|}
\hline A & .00100 \\
\hline B & .00074 \\
\hline C & .00048 \\
\hline D & .00022 \\
\hline E &. .00004 \\
\hline F &. .00030 \\
\hline G &. .00056 \\
\hline H &. .00082 \\
\hline I & -.00108 \\
\hline J &. .00134 \\
\hline K &. .00160 \\
\hline L &. .00186 \\
\hline M &. .00212 \\
\hline $\mathrm{N}$ &. .00238 \\
\hline $\mathrm{O}$ &. .00264 \\
\hline
\end{tabular}

Fig. 10a Typical shear strain conlours for $0^{\circ}$ graphite-epoxy losipescu specimen. 


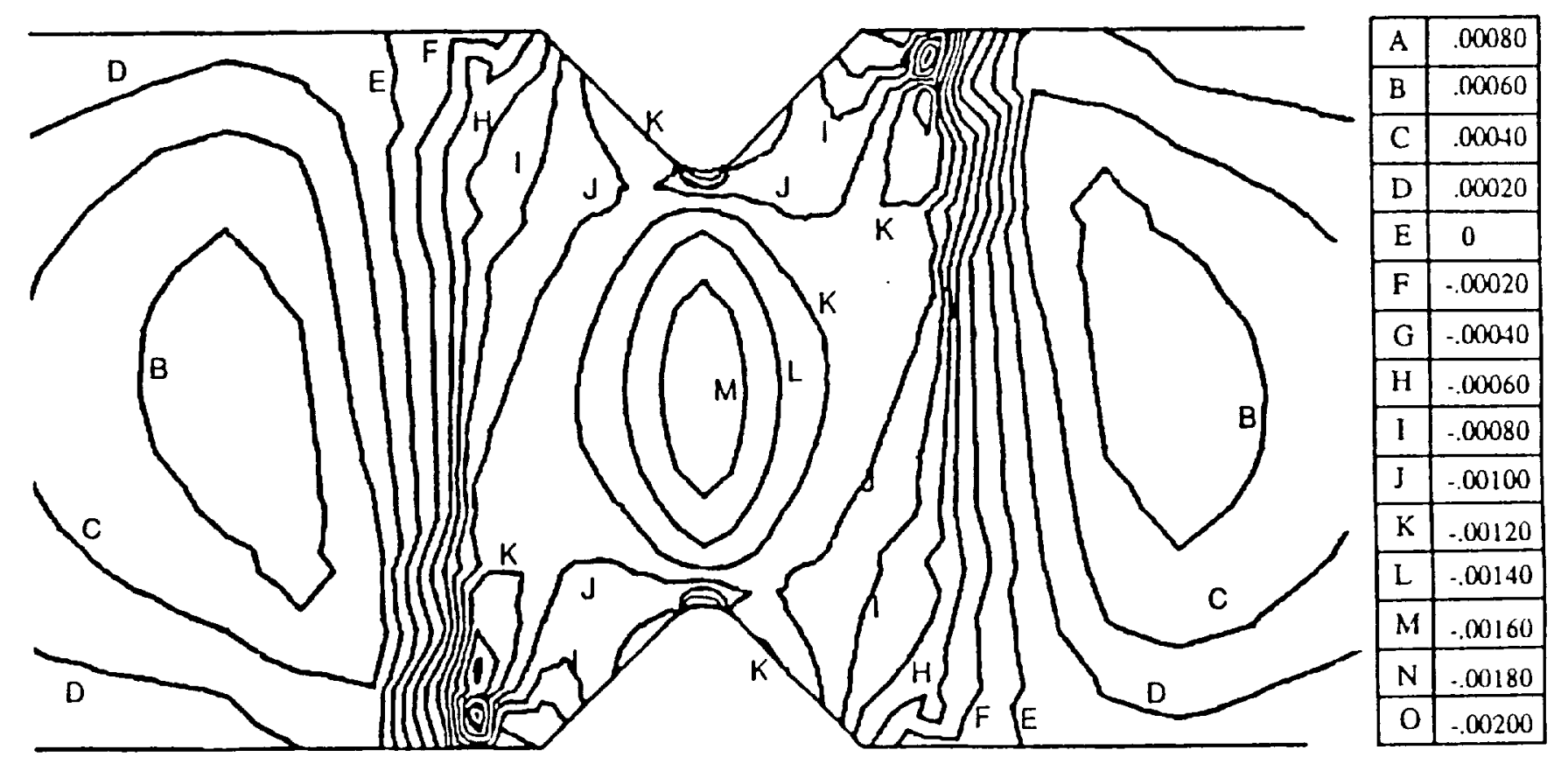

Fig. 10b Typical shear strain contours for $90^{\circ}$ graphite-epoxy Iosipescu specimen. 


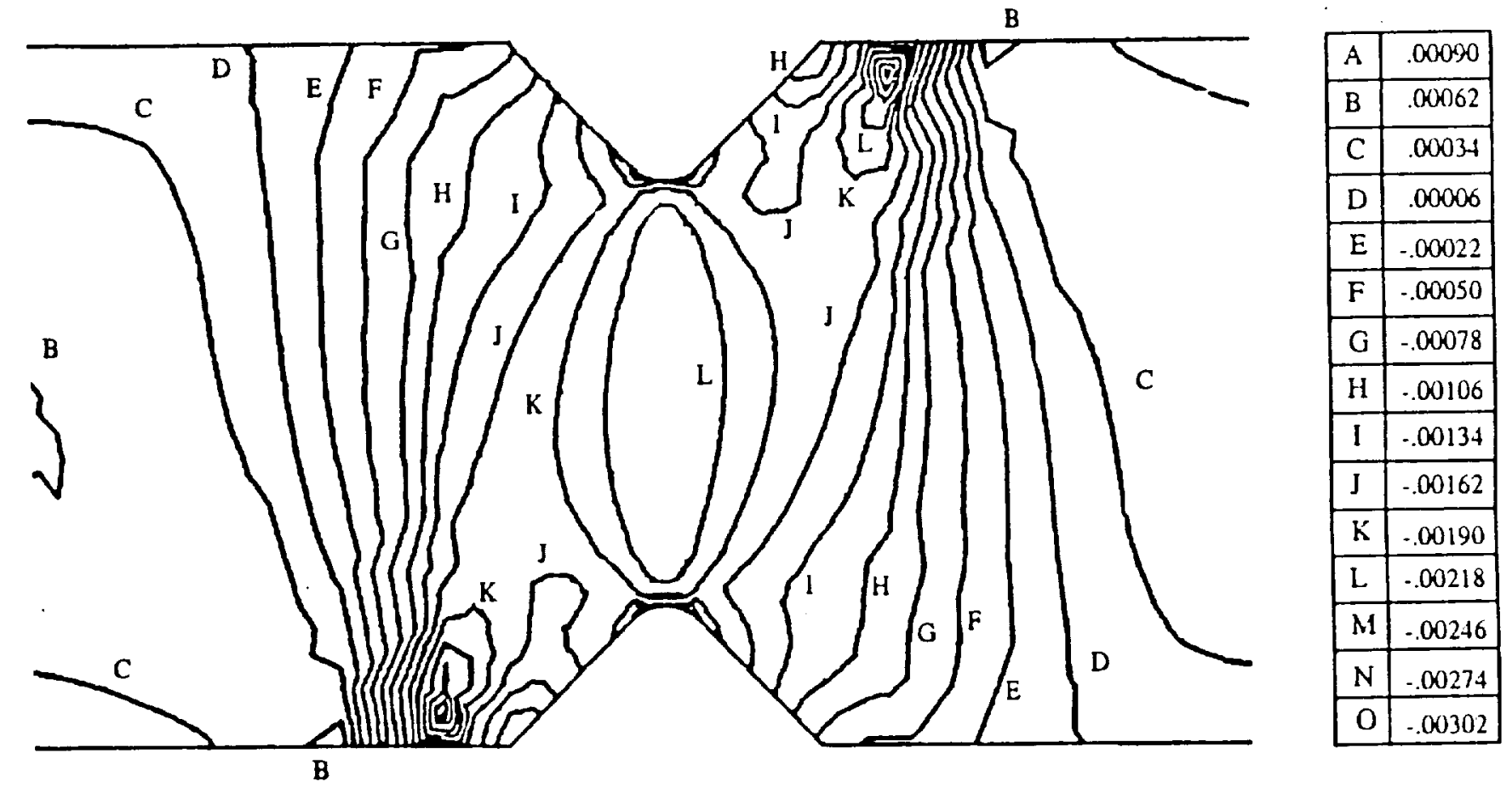

Fig. 10c Typical shear strain contours for $0^{\circ} / 90^{\circ}$ graphite-epoxy losipescu specimen. 


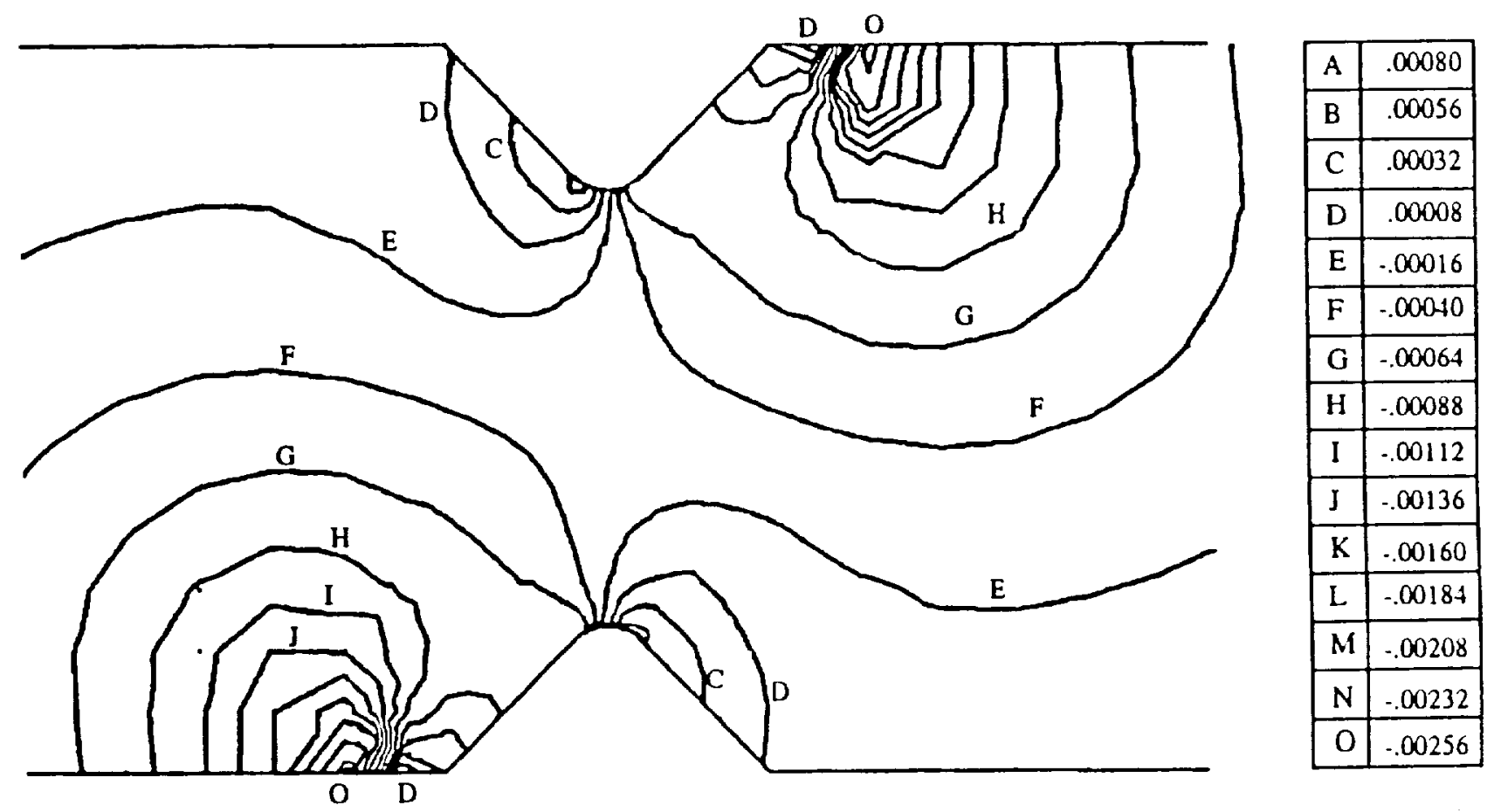

I

Fig. 11a Transverse normal strain $\left(\varepsilon_{y}\right)$ conlours for $0^{\circ}$ graphite-epoxy Iosipescu specimen. 


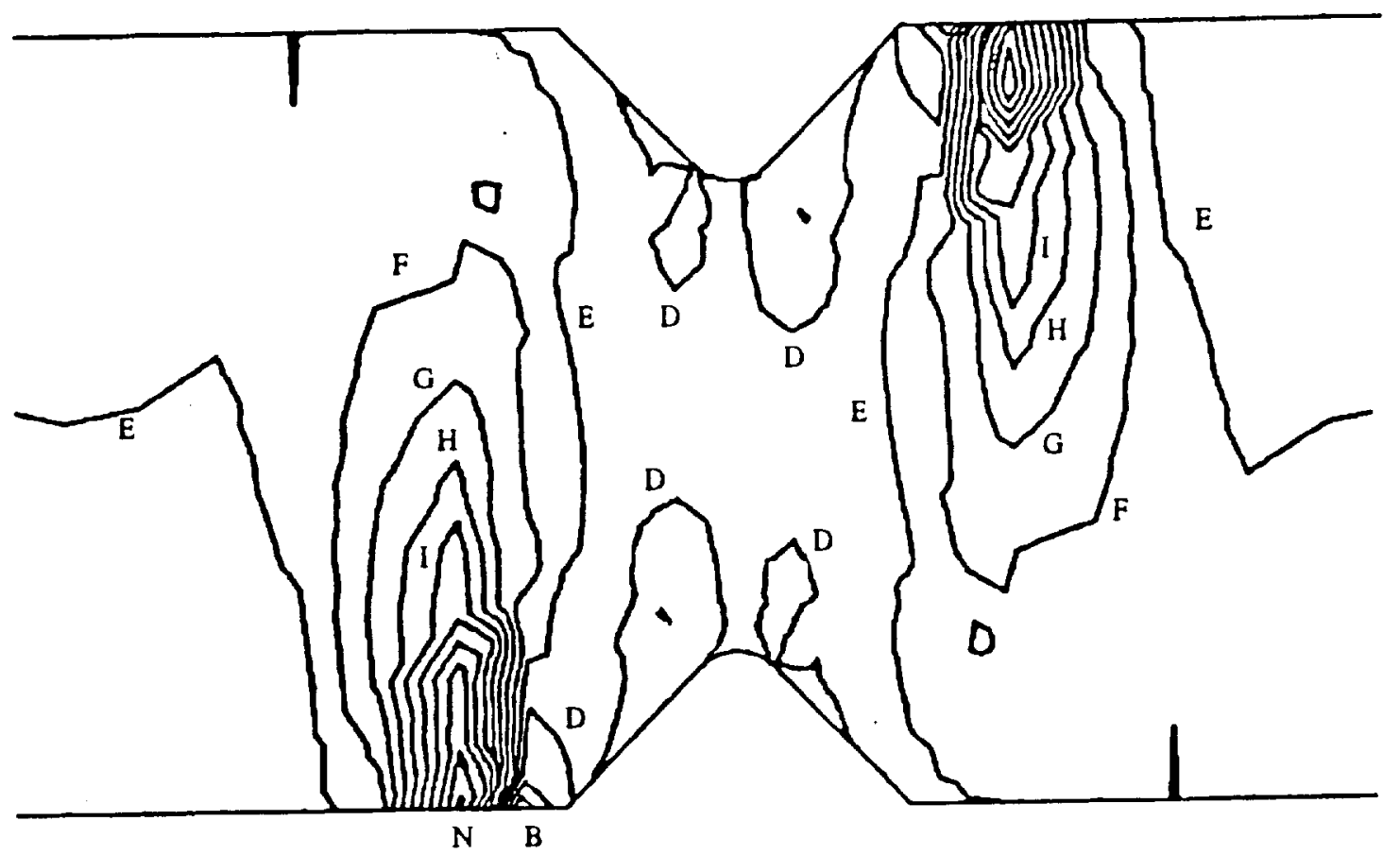

\begin{tabular}{|l|l|}
\hline $\mathrm{A}$ & .00022 \\
\hline $\mathrm{B}$ & .00016 \\
\hline $\mathrm{C}$ & .00010 \\
\hline $\mathrm{D}$ & .00004 \\
\hline $\mathrm{E}$ &. .00002 \\
\hline $\mathrm{F}$ &. .00008 \\
\hline $\mathrm{G}$ &. .00014 \\
\hline $\mathrm{H}$ &. .00020 \\
\hline $\mathrm{I}$ &. .00026 \\
\hline $\mathrm{J}$ & .00032 \\
\hline $\mathrm{K}$ &. .00038 \\
\hline $\mathrm{L}$ &. .00044 \\
\hline $\mathrm{M}$ &. .00050 \\
\hline $\mathrm{N}$ &. .00056 \\
\hline $\mathrm{O}$ &. .00062 \\
\hline
\end{tabular}

Fig. $11 \mathrm{~b}$ Transverse normal strain $\left(\varepsilon_{y}\right)$ contours for $90^{\circ}$ graphite-epoxy Iosipescu specimen. 

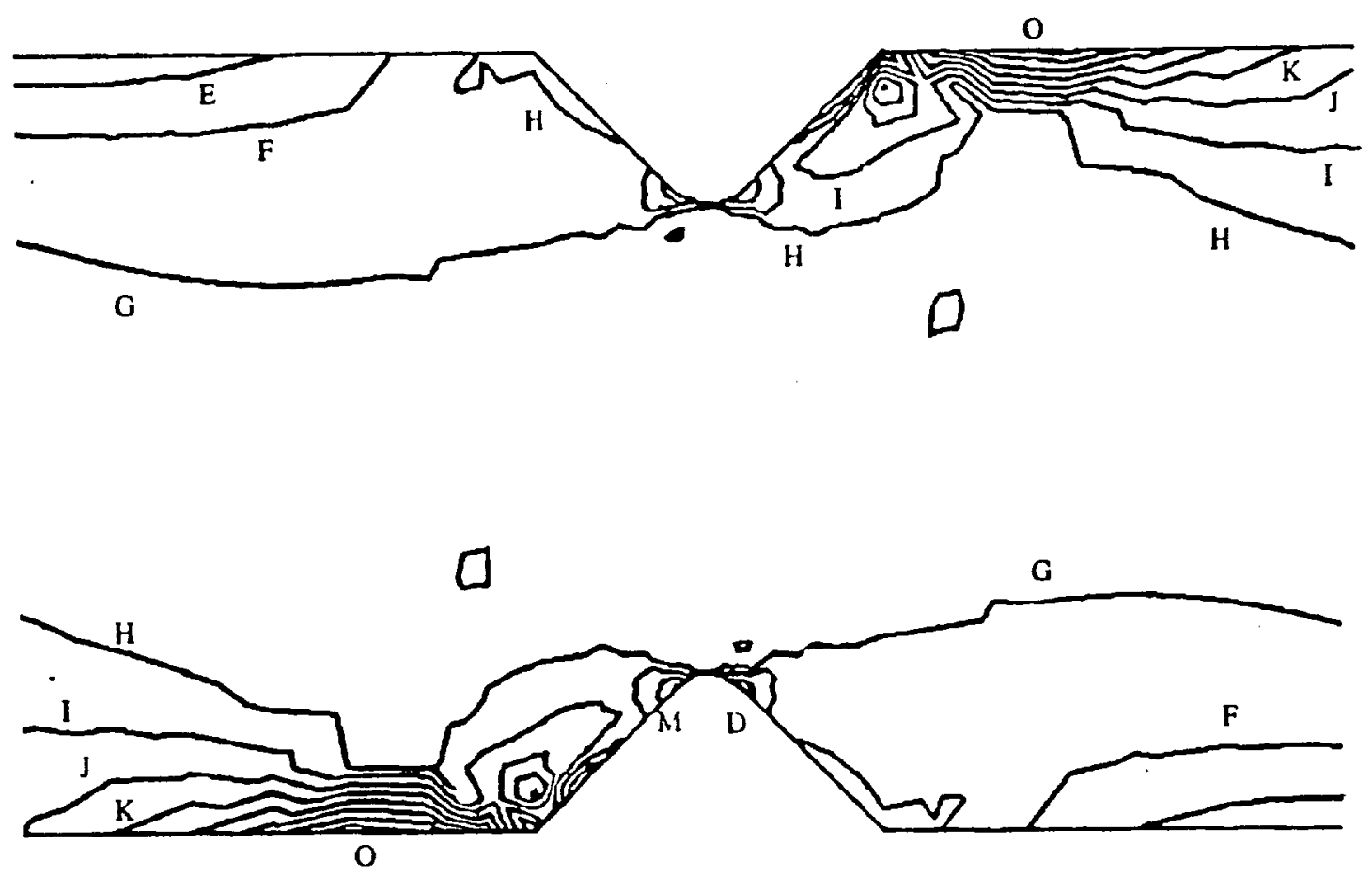

\begin{tabular}{|c|c|}
\hline A & .00028 \\
\hline$B$ & .00024 \\
\hline$C$ & .00020 \\
\hline$D$ & .00015 \\
\hline$E$ & .00011 \\
\hline F & .00007 \\
\hline$G$ & .00003 \\
\hline$H$ & .00001 \\
\hline$I$ &. .00006 \\
\hline$J$ & -.00010 \\
\hline$K$ & .00014 \\
\hline$L$ & .00018 \\
\hline$M$ & .00022 \\
\hline$N$ & .00027 \\
\hline$O$ & .00031 \\
\hline
\end{tabular}

Fig. 12a Longitudinal normal strain $\left(\varepsilon_{x}\right)$ contours for $0^{\circ}$ graphite-epoxy losipescu specimen. 


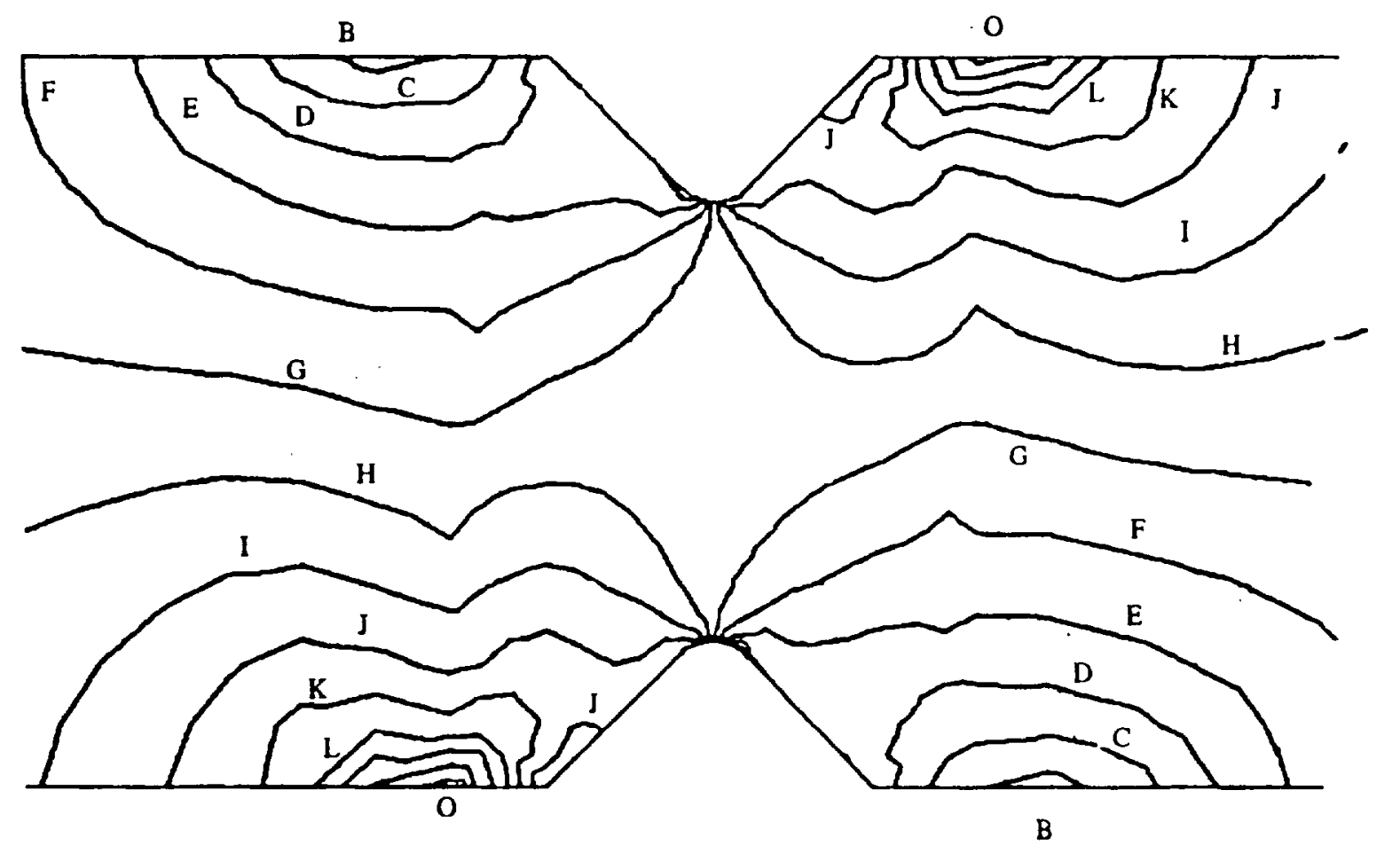

\begin{tabular}{|c|c|}
\hline $\mathrm{A}$ & .00180 \\
\hline $\mathrm{B}$ & .00152 \\
\hline $\mathrm{C}$ & .00124 \\
\hline $\mathrm{D}$ & .00096 \\
\hline $\mathrm{E}$ & .00068 \\
\hline $\mathrm{F}$ & .00010 \\
\hline $\mathrm{G}$ & .00012 \\
\hline $\mathrm{H}$ &. .00016 \\
\hline $\mathrm{I}$ &. .00041 \\
\hline $\mathrm{J}$ & .00072 \\
\hline $\mathrm{K}$ &. .00100 \\
\hline $\mathrm{L}$ &. .00128 \\
\hline $\mathrm{M}$ & .00156 \\
\hline $\mathrm{N}$ &. .00184 \\
\hline $\mathrm{O}$ & .00212 \\
\hline
\end{tabular}

Fig. 12b Longitudinal normal strain $\left(\varepsilon_{x}\right)$ contours for $90^{\circ}$ graphite-epoxy losipescu specimen. 


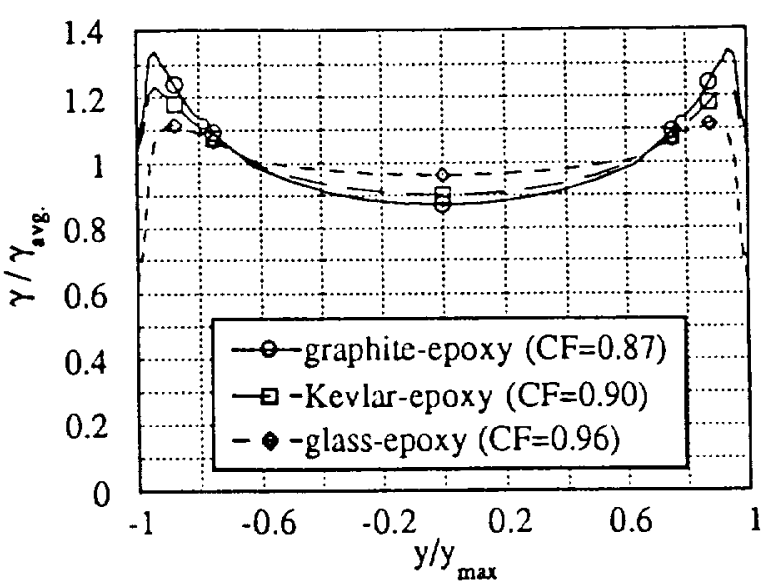

(a)

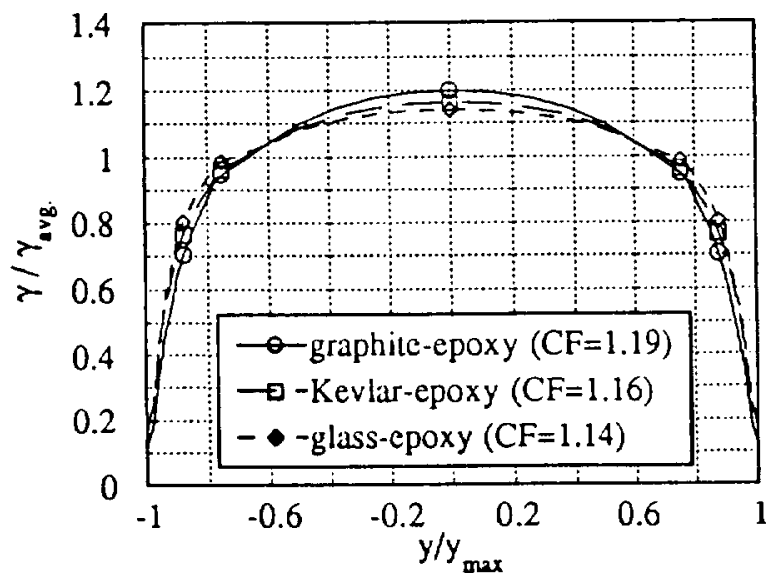

(b)

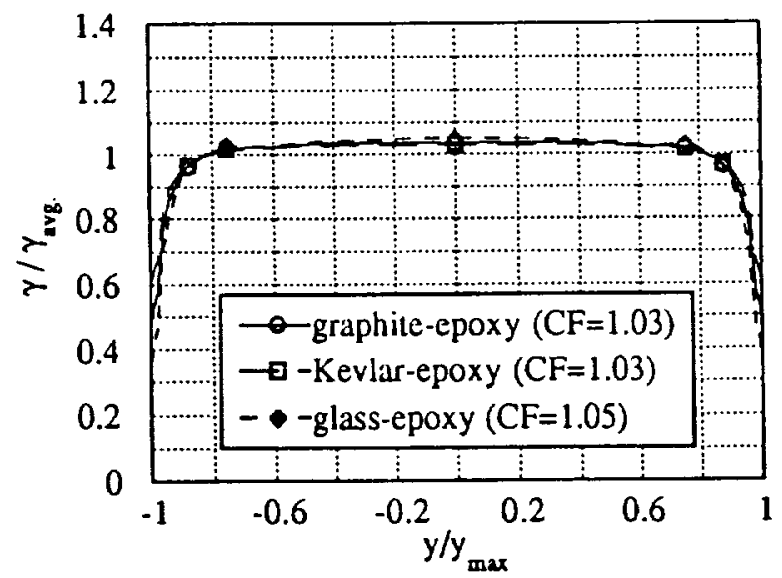

(c)

Fig. 13. Shear strain distribution at $x=0$ for (a) $0^{\circ}$, (b) $90^{\circ}$, (c) $0^{\circ} / 90^{\circ}$ graphite-epoxy, Kevlar-epoxy and glass-epoxy specimens. 


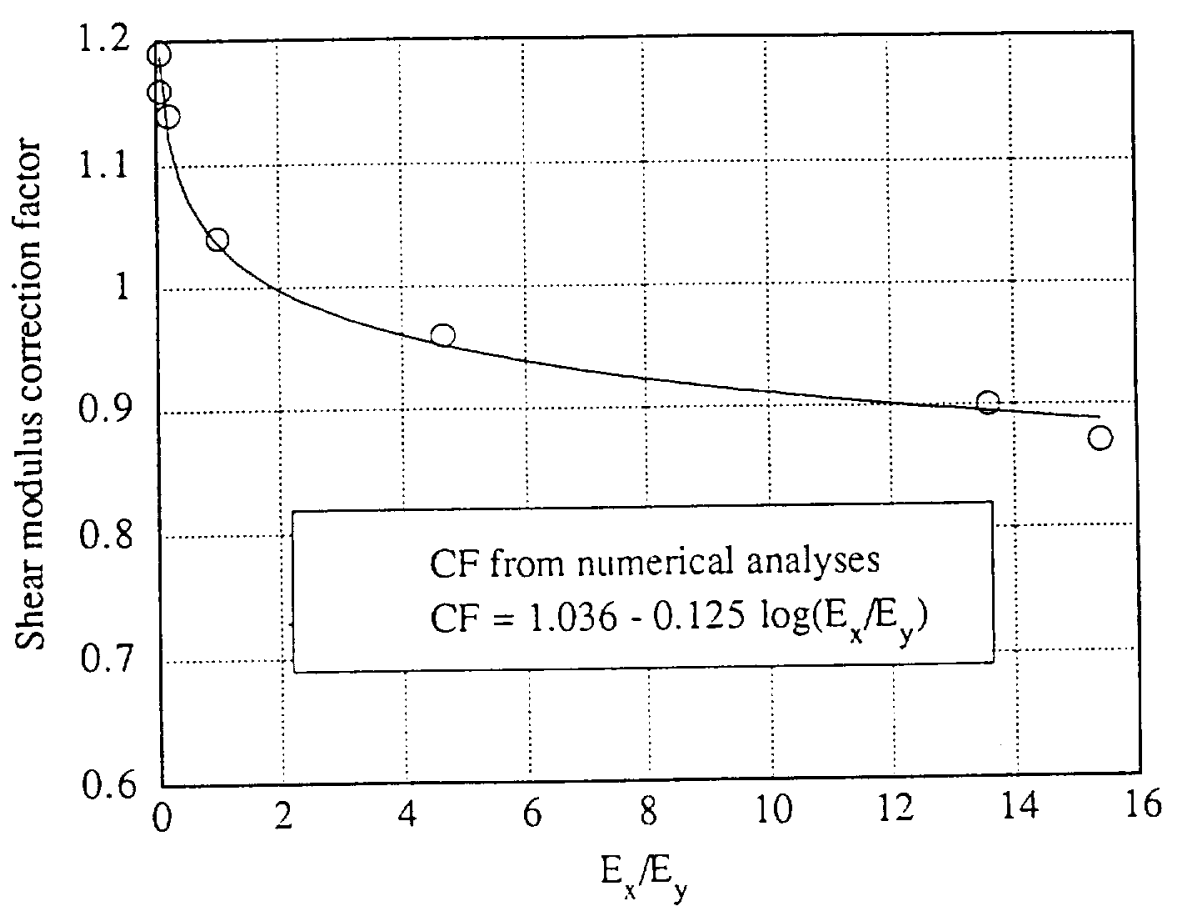

Fig. 14. Correction factor vs. material orthotropic ratio. 


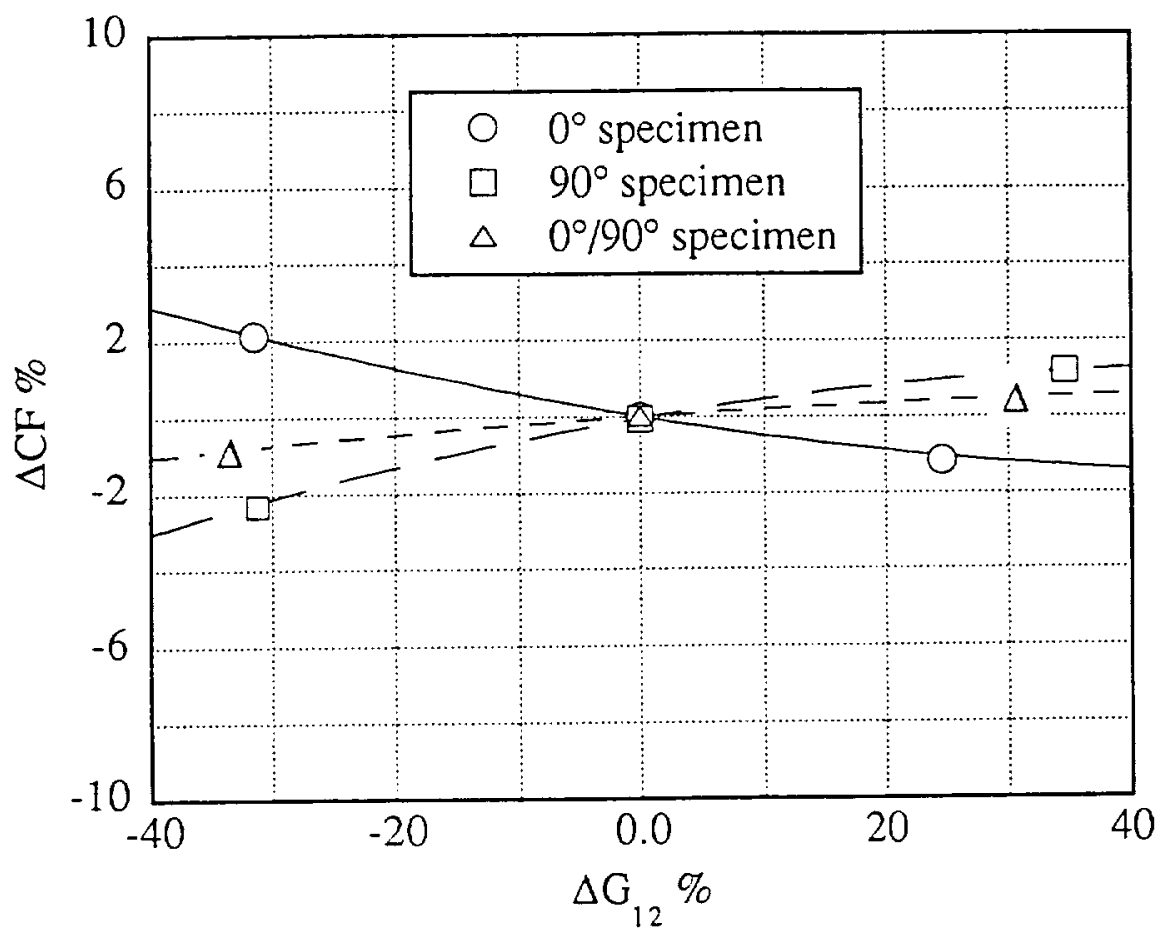

Fig. 15. Sensitivity of the correction factors to shear moduli for graphite-epoxy Iosipescu specimen. 


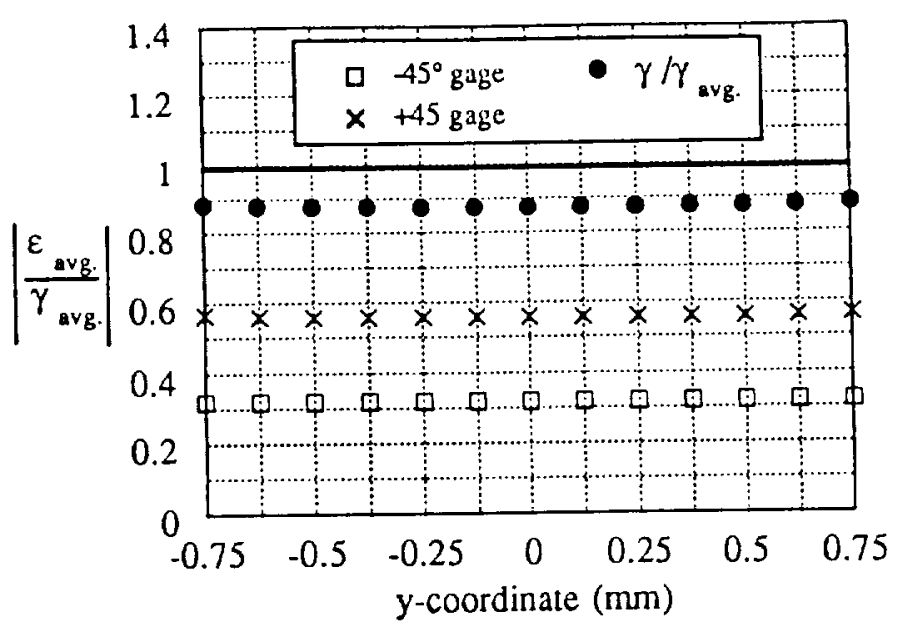

(a)

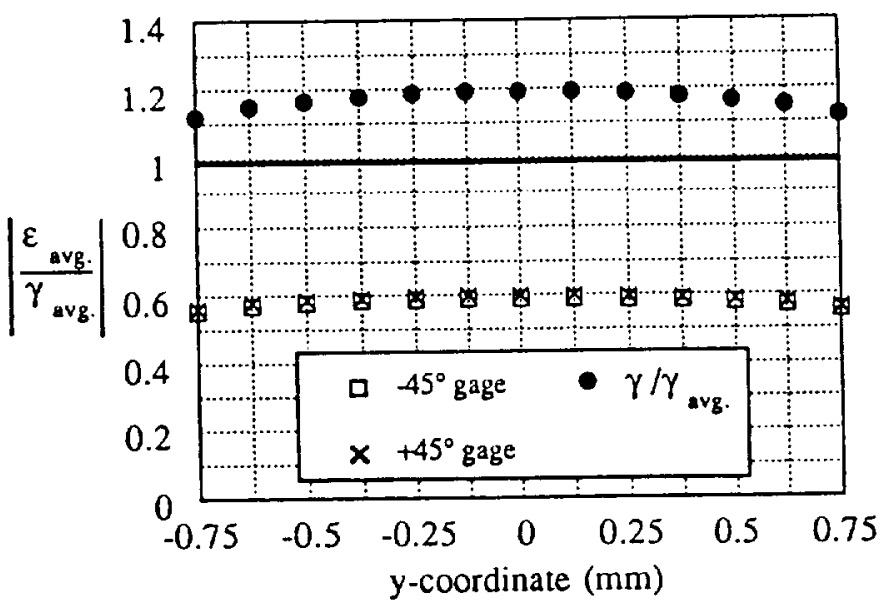

(b)

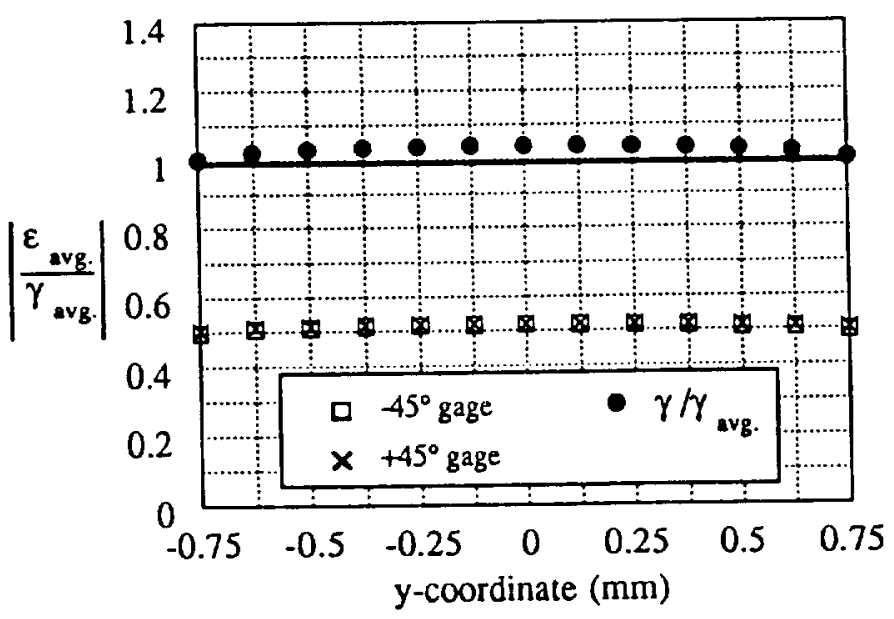

(c)

Fig. 16. Normalized strains of $\pm 45^{\circ}$ gages from finite element analysis for (a) $0^{\circ}$, (b) $90^{\circ}$, (c) $0^{\circ} / 90^{\circ}$ graphite-epoxy Iosipescu specimen. 


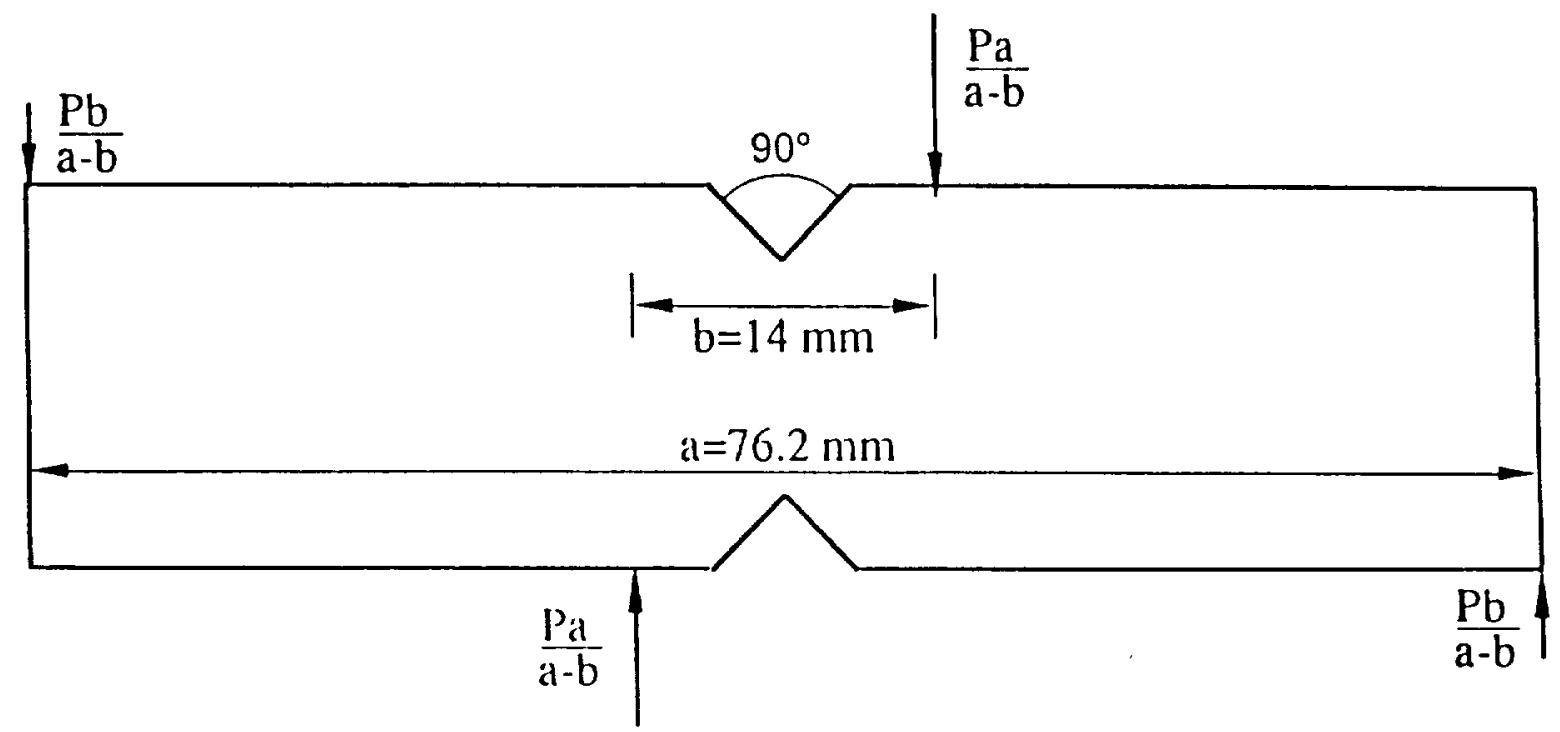

(a)

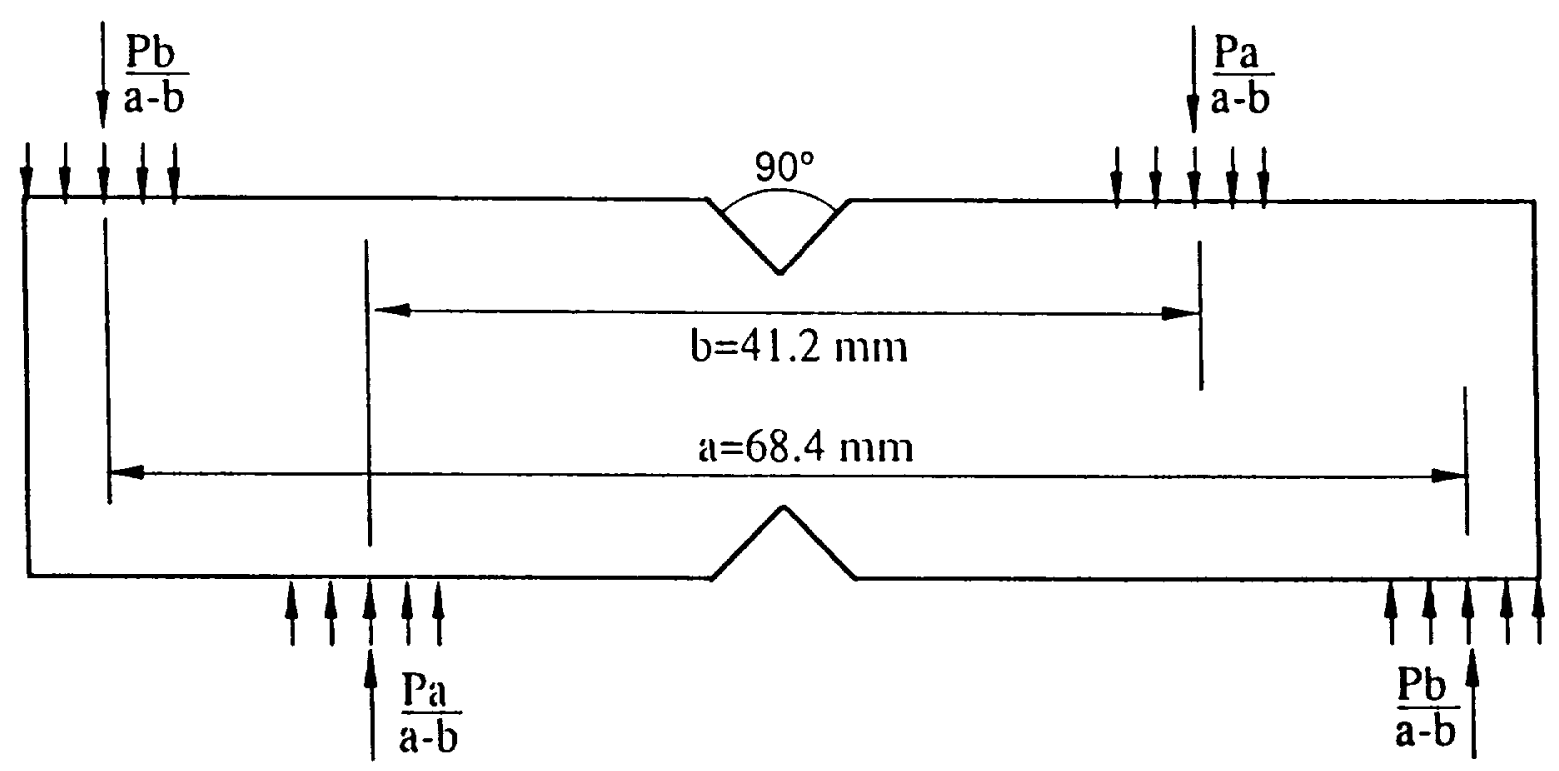

(b)

Fig. 17. Force couple finite element models of Iosipescu specimen tested in Wyoming fixture, (a)concentrated load model, (b) distributed load model. 


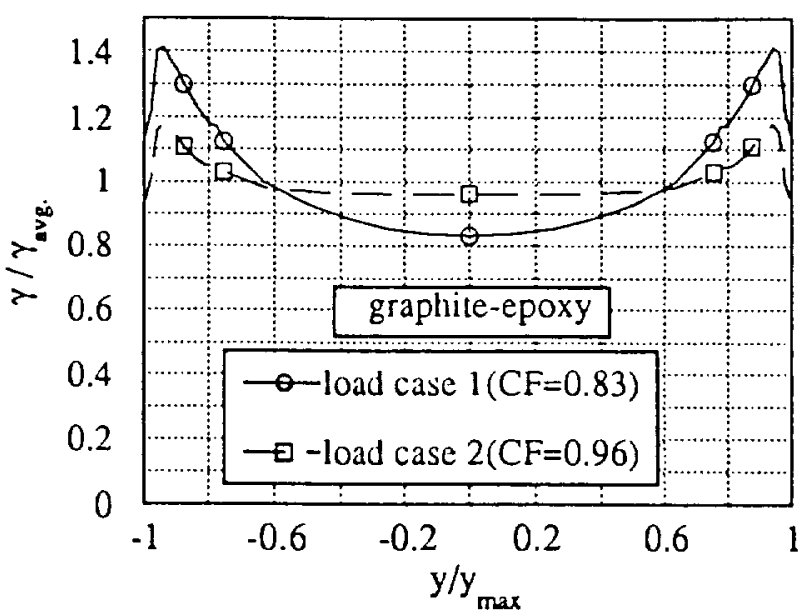

(a)

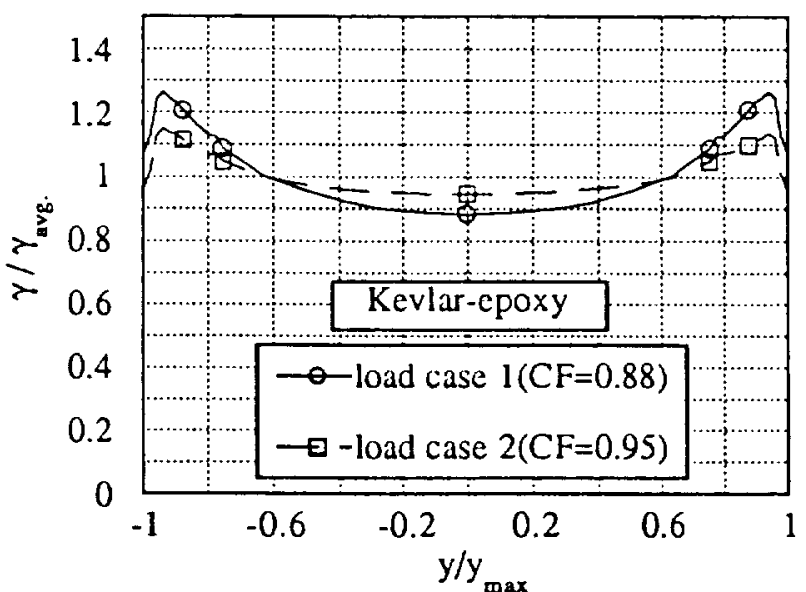

(b)

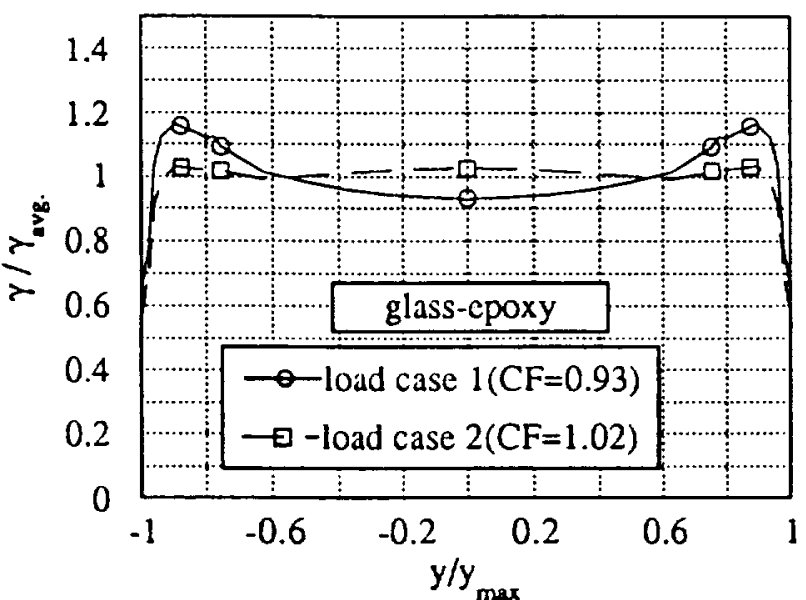

(c)

Fig. 18. Load point effect on the shear strain distribution at $x=0$ for (a) graphite-epoxy, (b) Kevlar-epoxy, (c) glass-epoxy $0^{\circ}$ specimen. 


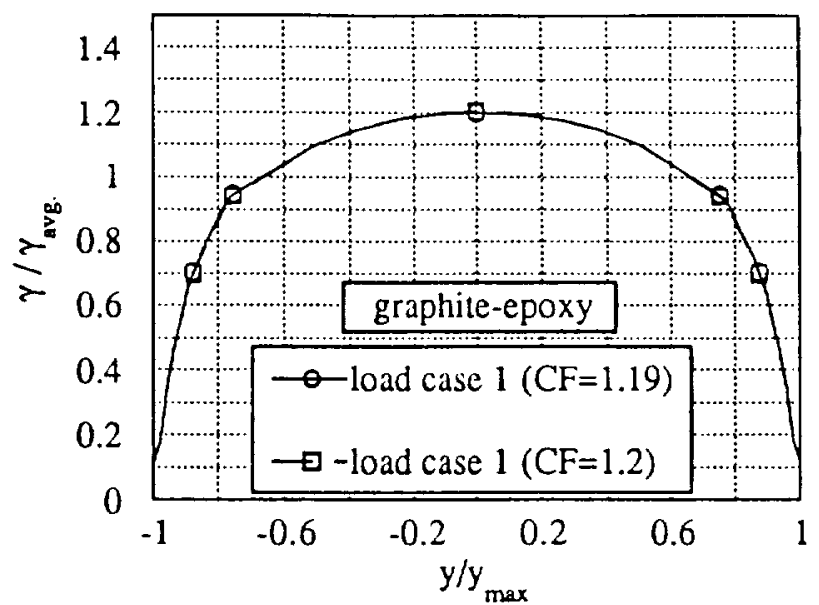

(a)

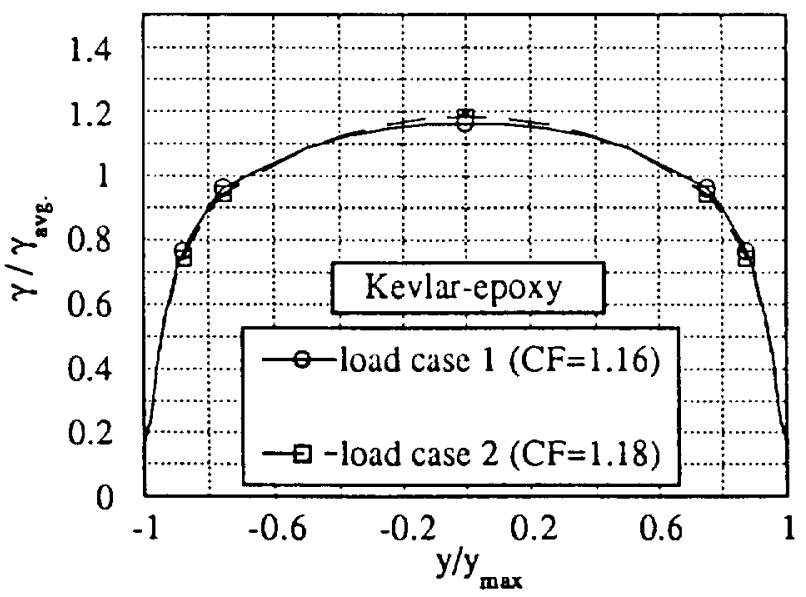

(b)

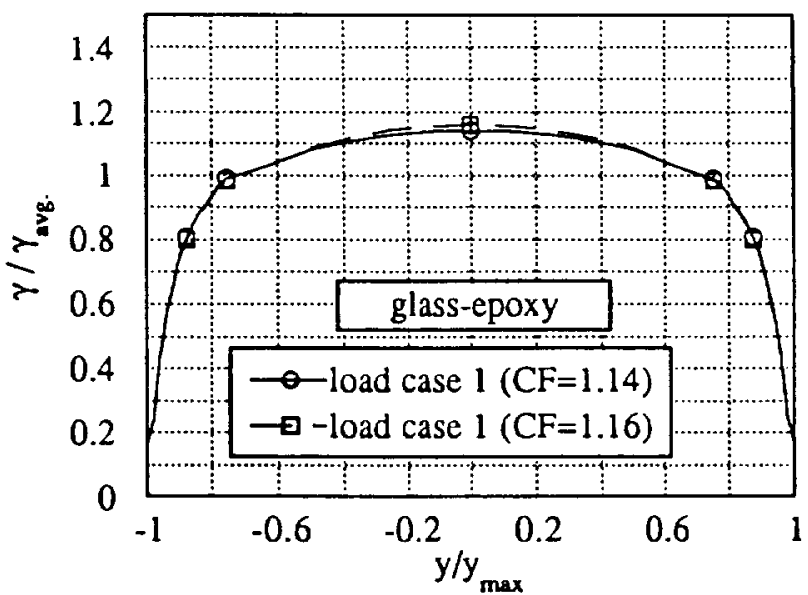

(c)

Fig. 19. Load point effect on the shear strain distribution at $x=0$ for (a) graphite-epoxy, (b) Kevlar-epoxy, (c) glass-epoxy $90^{\circ}$ specimen. 


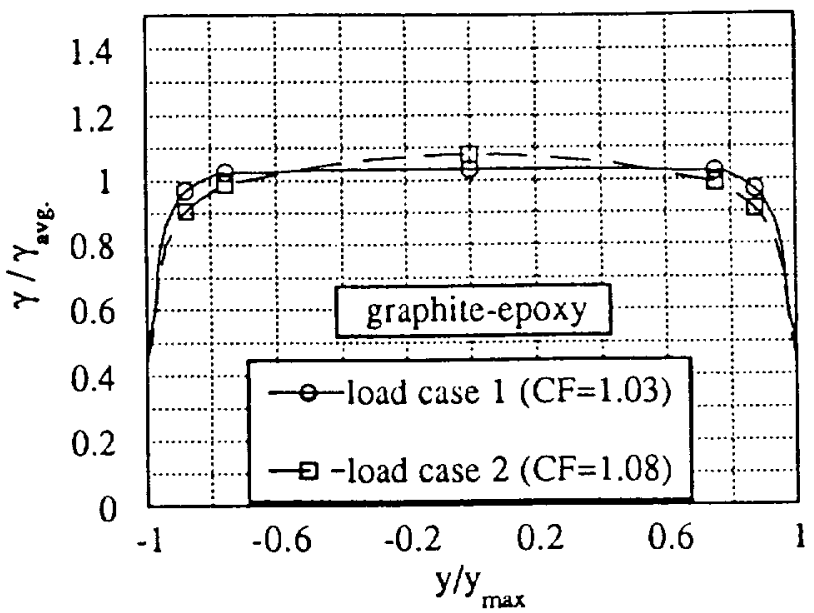

(a)

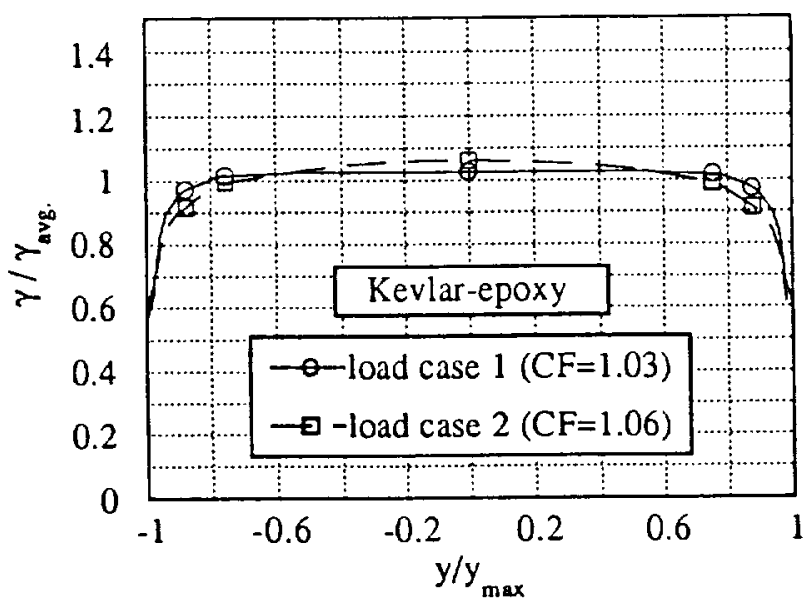

(b)

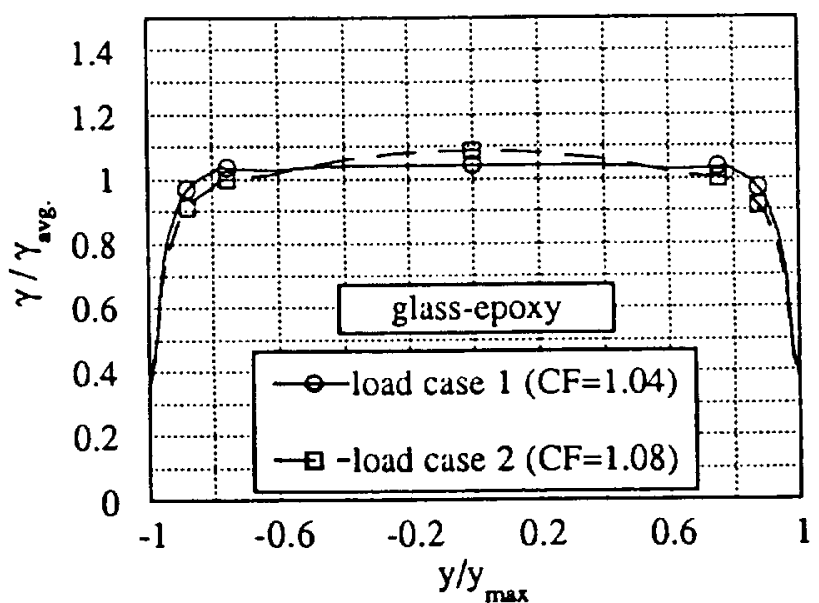

(c)

Fig. 20. Load point effect on the shear strain distribution at $x=0$ for (a) graphite-epoxy, (b) Kevlar-epoxy, (c) glass-epoxy $0^{\circ} / 90^{\circ}$ specimen. 